\title{
Blood supply of the optic nerve head and its role in optic atrophy, glaucoma, and oedema of the optic disc
}

\author{
SOHAN SINGH HAYREH \\ Institute of Ophthalmology, University of London
}

The blood supply of the optic disc is an important and a fascinating subject in ophthalmology. Since the time of Haller (1 754) and Zinn (1 755) it has remained the centre of controversy. The literature on the subject has recently been reviewed in detail by Hayreh (1963a), François and Neetens (1966), and Bonamour, Brégeat, Bonnet, and Juge (1968). The recent introduction of fluorescence angiography has made a significant contribution to the subject because it enables us to study the microcirculation in vivo.

\section{PART I BLOOD SUPPLY OF THE OPTIC NERVE HEAD}

The following account of the blood supply of the optic nerve head is based on my three types of investigations:

(i) Anatomical and histological studies were carried out in 100 human eyes by Neoprene látex injection and in ten human eyes by serial sectioning of the optic nerve (Hayreh, 1958; 1962b, 1963a, 1963c, 1966; Hayreh and Dass, 1959; Singh and Dass, 1960). These studies, though valuable, had many limitations.

(ii) Fluorescence fundus angiographic studies were carried out in patients with normal optic discs and with various lesions.

(iii) Experimental studies in rhesus and cynomolgus monkeys using fluorescence fundus angiography (Hayreh and Perkins, 1968, 1969) gave some important information which could not be obtained from $(i)$ and $(i i)$.

For descriptive purposes the region of the optic nerve head can be divided into three parts to consider its blood supply (Fig. I, overleaf).

\section{Arterial supply of the optic disc}

(a) Region of the lamina cribrosa

This is supplied by centripetal fine branches from the so-called arterial circle of Zinn or more often directly from the branches of the posterior ciliary arteries. I should like to

This paper was presented at the International Symposium on Fluorescein Angiography, Albi (France), June 9-14, 1969

Received for publication July 14,1969

Address for reprints: Department of Ophthalmology, University of Edinburgh, Chalmers Street, Edinburgh EH3 9HA 


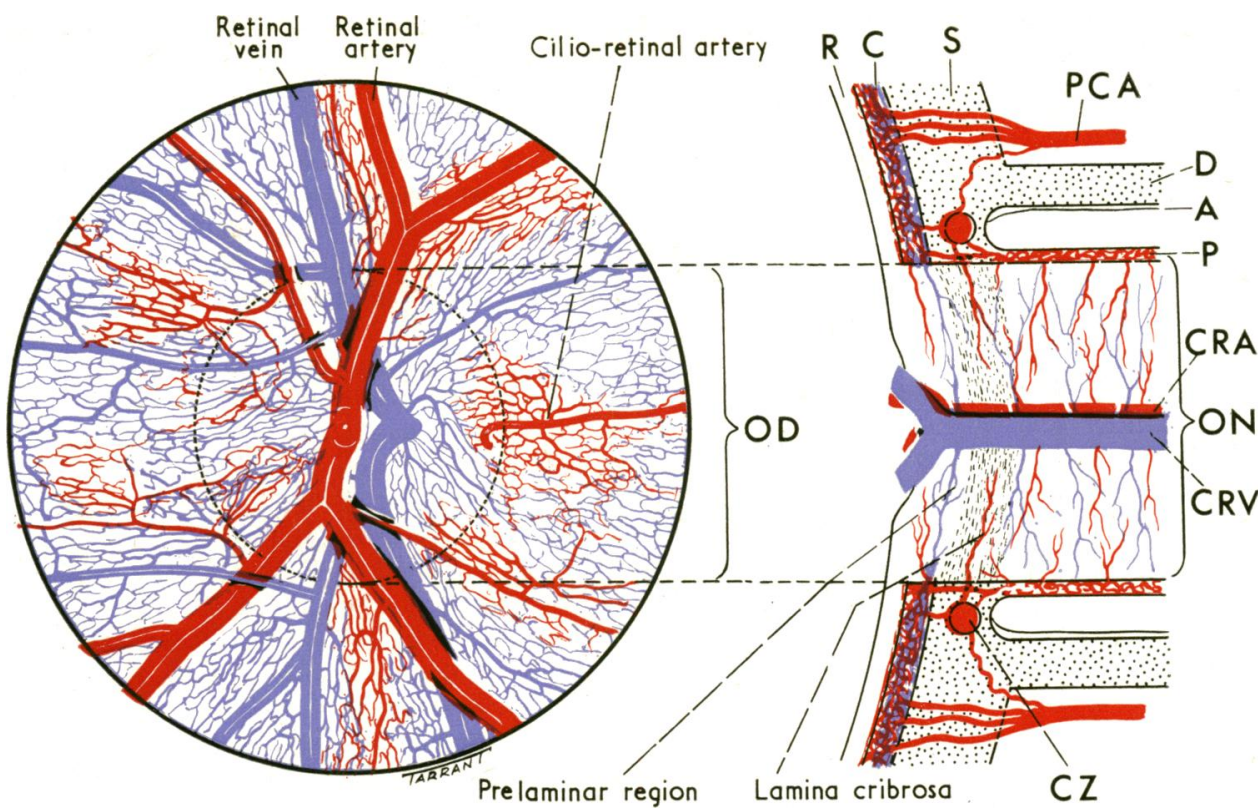

C Z

FIG. I Diagrammatic representation of blood supply of optic nerve head (from Hayreh and Perkins, 1968)

$\begin{array}{llllll}\text { A } & \text { arachnoid } & \text { CZ } & \text { circle of Zinn and Haller } & \text { P } & \text { pia } \\ \text { C } & \text { choroid } & \text { D } & \text { dura } & \text { PCA } & \text { posterior ciliary arteries } \\ \text { GRA } & \text { central retinal artery } & \text { OD } & \text { optic disc } & \text { R } & \text { retina } \\ \text { CRV } & \text { central retinal vein } & \text { ON } & \text { optic nerve } & \text { s } & \text { sclera }\end{array}$

stress at this stage that a typical circle of Zinn is an uncommon finding and, when present, ڤે is quite often an incomplete circle. The central artery of the retina makes no contribution $\stackrel{\varnothing}{\AA}$ to this region. The vessels lie in the fibrous septa of the lamina cribrosa and form a dense $\overline{0}$ capillary plexus.

\section{(b) Prelaminar region}

This is supplied mainly by centripetal branches from the peripapillary choroidal vessels. These seem to be end vessels with little communication with the other vessels, as judged from fluorescence angiographic studies, thus having a sectoral distribution in the prelaminar region. This region may also receive some contribution from the vessels in the lamina cribrosa region. The central artery of the retina does not usually contribute to $\frac{\text { o }}{\partial}$ this region. The fluorescence studies strongly suggest that the temporal part of this region $\frac{7}{0}$ is much more vascular than the rest and receives its maximum contribution from the choroid.

The blood supply of the nasal part of the prelaminar region is still not clearly understood. $N$ The supply from the peripapillary choroid to this area is not as profuse and constant as to the temporal region. Presumably it comes mainly from the vessels in the underlying region of the lamina cribrosa. More work needs to be done to elucidate the source of $\stackrel{\circ}{\odot}$ blood supply to the nasal part in the prelaminar region.

(c) Surface layer of the optic disc

This contains the main retinal vessels and a large number of capillaries in addition to some $\stackrel{\mathbb{D}}{\mathbb{D}}$ small vessels. The capillaries on the surface of the disc are derived from branches of the 
retinal arterioles which most commonly arise from the main retinal arterioles in the circumpapillary region and less often on the disc. In this part of the disc it is not uncommon to find vessels of choroidal origin derived from the adjacent prelaminar part of the disc; these are mostly seen in the temporal sector of the disc and one of these may enlarge to form the cilio-retinal artery. The capillaries on the surface of the disc are continuous with the capillaries of the peripapillary retina and with the long radial peripapillary capillary network described by Michaelson and Campbell (1940). On the disc these capillaries are mostly of a venous nature and drain into the central retinal vein or its tributaries. It is important to note that all the capillaries in the optic nerve head are interconnected, being continuous posteriorly with those of the retrolaminar part of the optic nerve and anteriorly with the adjoining retina. The retinal capillaries are supplied solely by the central artery of the retina except for the occasional cilio-retinal artery. In the retrolaminar part of the optic nerve the blood is mainly supplied by the intraneural centrifugal branches of the central artery of the retina with centripetal contribution from the pial branches from the choroidal arteries, circle of Zinn, central artery of the retina, and direct from the ophthalmic artery.

\section{Venous drainage of the optic disc}

This is mainly carried out by the central retinal vein. The prelaminar region also drains into the choroidal veins. There is no venous channel corresponding to the circle of Zinn. The central retinal vein communicates with the choroidal circulafion in the prelaminar region which may assume importance in acting as collateral channels to drain away the blood in patients with complete central retinal vein block behind the lamina cribosa.

I should like to stress that there is a good deal of variation between individuals in the pattern of the blood supply.

The contribution made by the ciliary circulation to the blood supply of the optic disc is demonstrated by the following examples of fluorescence fundus angiography in man:

I. PREARTERIAL FILLING OF THE OPTIC DISG

It is now well known that the choroidal circulation fills before the retinal circulation (prearterial filling). Fluorescence angiography often reveals filling of the capillaries of the optic disc before the dye has reached the central artery of the retina, most commonly in the temporal sector (Fig. 2, overleaf).

\section{GENTRAL RETINAL ARTERY OGGLUSION}

(a) Filling of the fine vessels in the optic disc

It is a common and well-established observation that in occlusion of the central artery of the retina the capillaries of the optic disc usually fill while the central artery of the retina is empty of the dye (Hayreh, r966; Hill, r966; David, Norton, Gass, and Beauchamp, 1967; Snyder, Allen, and Frazier, I967; Hayreh and Perkins, I968; Kroll, I968; Shikano and Shimizu, I968; Gass, I969; and many others) (Fig. 3, overleaf).

\section{(b) Cilio-retinal anastomoses after central retinal artery occlusion}

The case of a girl of 14 who developed a central retinal artery occlusion in one eye while recovering from herpes zoster ophthalmicus on the same side is interesting in demonstrating the ciliary contribution to the optic disc and cilio-retinal anastomoses. 
(a)

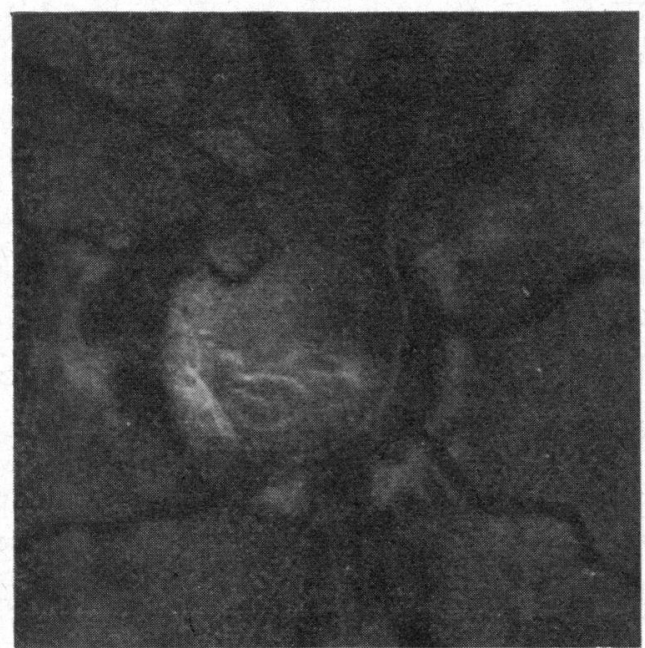

(b)

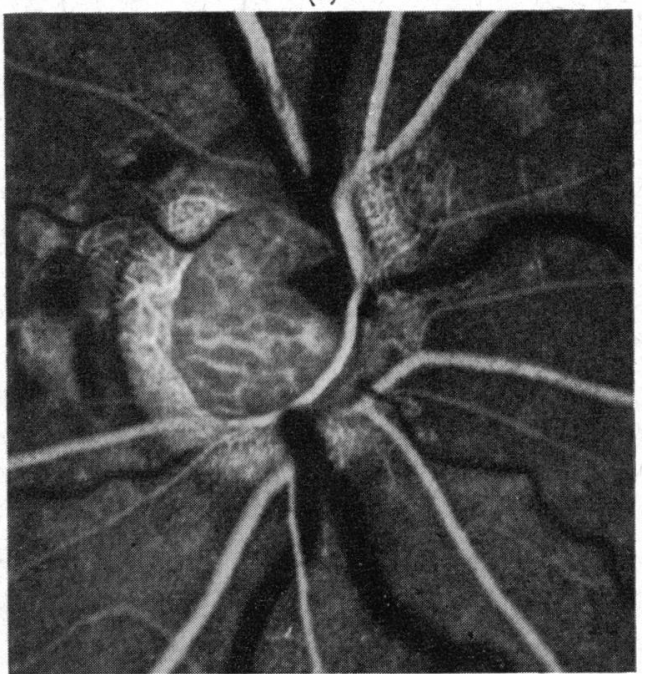

(a) filling of vessels of choroidal origin in the optic disc FIG. 2 Fluorescence angiograms of normal eye showing (a)
during the preretinal-arterial phase of the transit of dye which is more marked in (b)

(3)

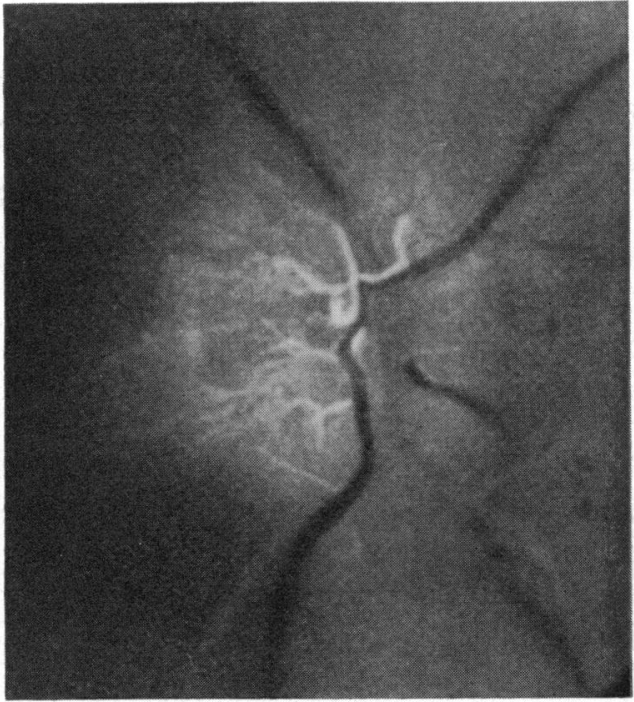

(4)

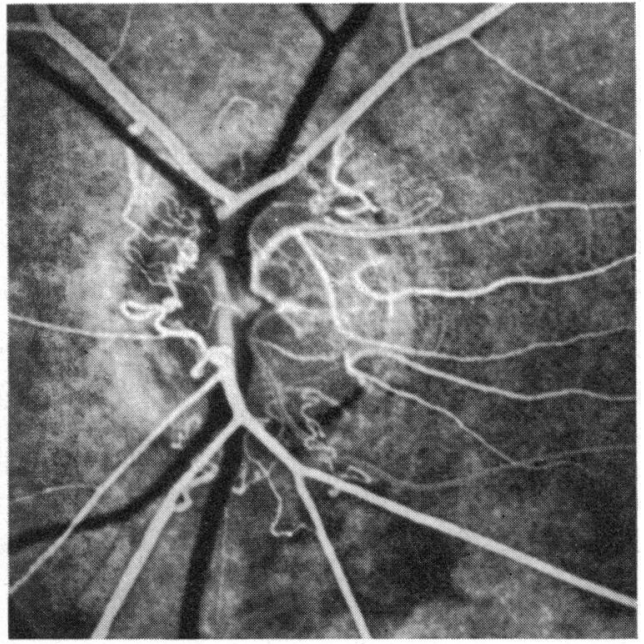

FIG. 3 Fluorescence angiogram in a patient with central retinal artery occlusion, showing filling of vessels of $\frac{0}{\mathrm{O}}$ choroidal origin in the disc, with no filling of the central retinal artery

FIG. 4 Fluorescence angiogram in a patient who had had a central retinal artery occlusion 9 months before, N showing filling of the cilio-retinal vessels, vessels of choroidal origin in the disc, retinal arterioles, and cilio-retinal $\mathrm{N}$ anastomoses on the disc

She had a small cilio-retinal artery on the temporal side of this eye; 9 months after the block, fluorescence angiography showed normal filling of the fine vessels on the temporal part of the optic :disc. Also a large number of vessels on the disc were seen to be connected at one end with the $\frac{T}{0}$ retinal arteries in the peripapillary region and at the other end with deep capillaries in the disc $\stackrel{\vec{D}}{\mathbb{D}}$ (Fig. 4). Part of the circulation to the retinal arteries was being derived from the disc vessels of $\frac{O}{\mathbb{D}}$ ciliary origin. 


\section{RETINITIS PIGMENTOSA}

When the large peripapillary choroidal vessels are unmasked by degeneration of the overlying pigment epithelium, Bruch's membrane, and choriocapillaris in retinitis pigmentosa, the prearterial phase shows nicely the choroidal contribution to the optic disc (Fig. 5). In these patients the time interval between the filling of the choroidal and the retinal vessels is significantly prolonged-a state of affairs similar to that of a partial central retinal artery occlusion.

(a)

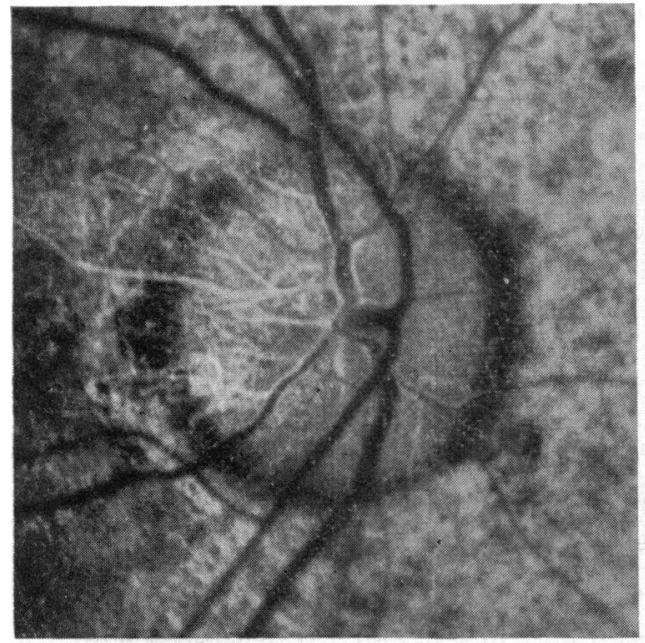

(b)

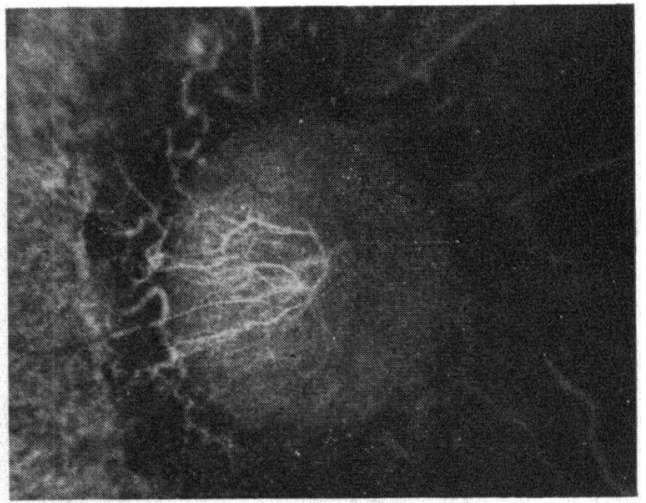

FIG. 5 Fluorescence angiograms in patients with retinitis pigmentosa during the preretinal-arterial phase

(a) shows filling of the prelaminar vessels of choroidal origin in the disc

(b) shows the peripapillary choroidal vessels very well

(a)

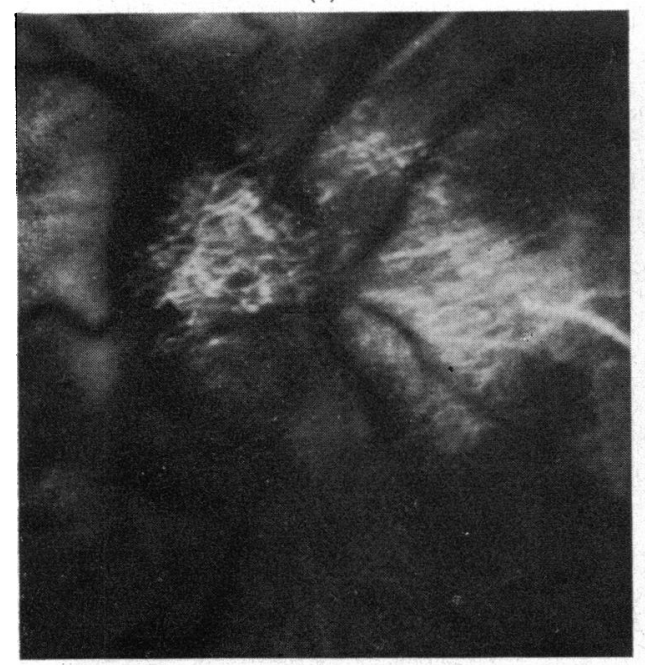

(b)

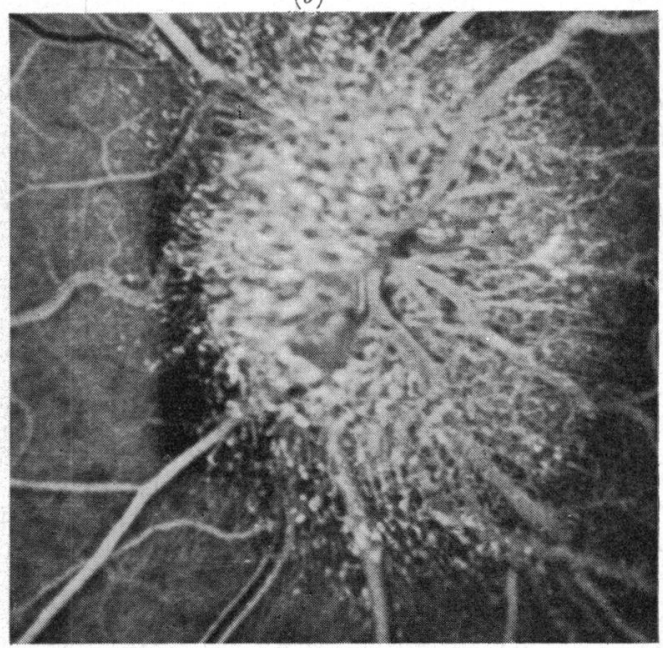

[Reproduced by courtesy of Mr. M. D. Sanders]

FIG. 6 Fluorescence angiograms in a patient with chronic oedema of the optic disc

(a) during preretinal-arterial phase, showing filling of cilio-retinal artery and ciliary vessels in the disc

(b) during arteriovenous phase 
4. GHRONIC OEDEMA OF THE OPTIC DISC

In a patient of Mr. M. D. Sanders', with chronic oedema of the optic disc due to an intracranial space-occupying lesion, fluorescence angiography revealed a large number of vessels of ciliary origin in the optic disc before the dye filled the central artery of the retina (Fig. 6, see page 725).

5. EXPERIMENTAL STUdies IN RHESUS AND GYNOMOLGUS MONKEYS The studies on the circulation of the optic nerve head in monkeys confirmed the findings in man, and provided conclusive evidence of the significant role played by the ciliary contribution to the blood supply of the optic nerve head. These findings have been reported at length in other communications (Hayreh and Perkins, 1968, I969). After injection of fluorescein into the common carotid artery, fluorescence angiograms of the disc

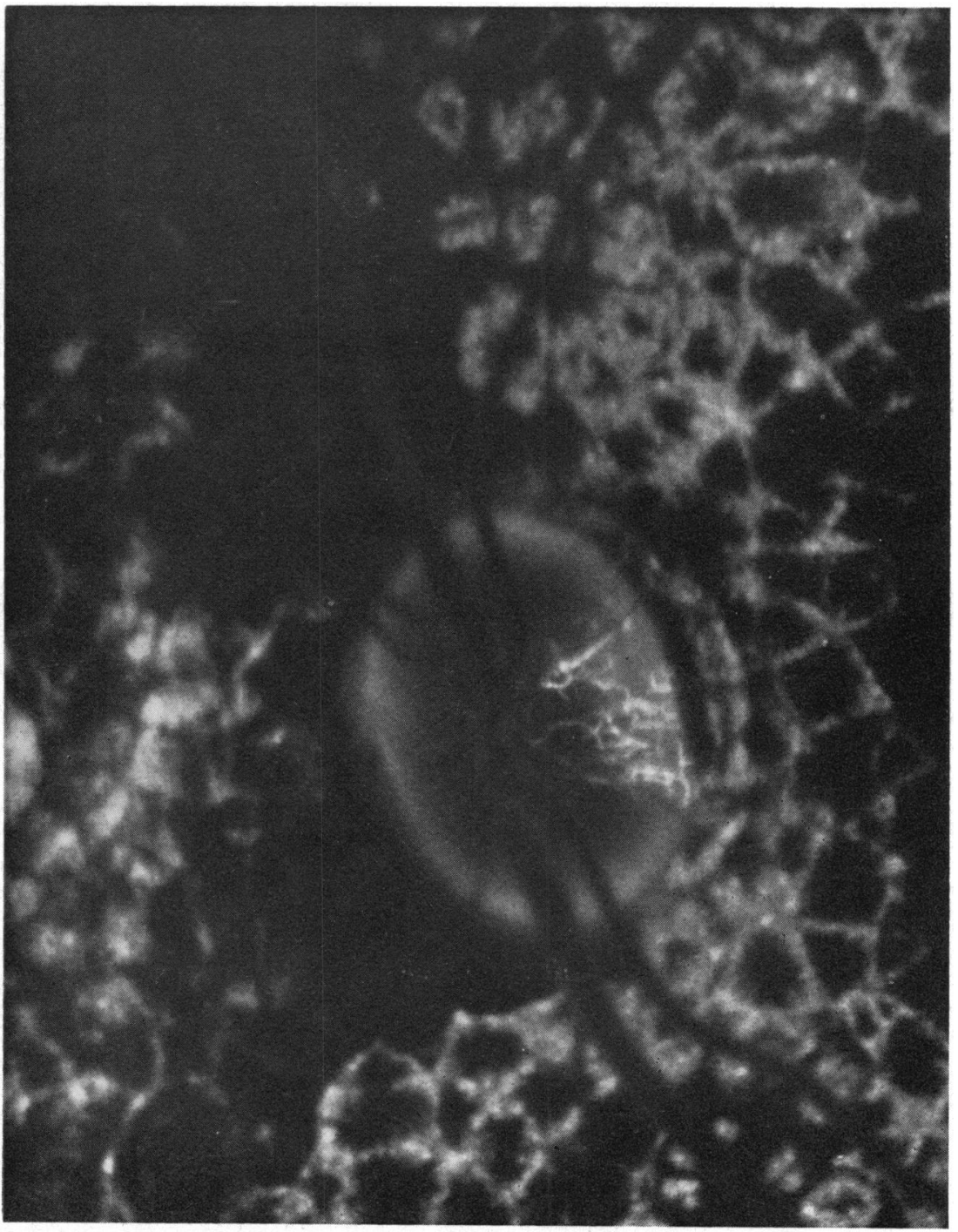

FIG. 7 Fluorescence angiogram in a monkey during the preretinal-arterial phase, showing early flling of the choroid and its contribution to the prelaminar region of the disc 
(a)

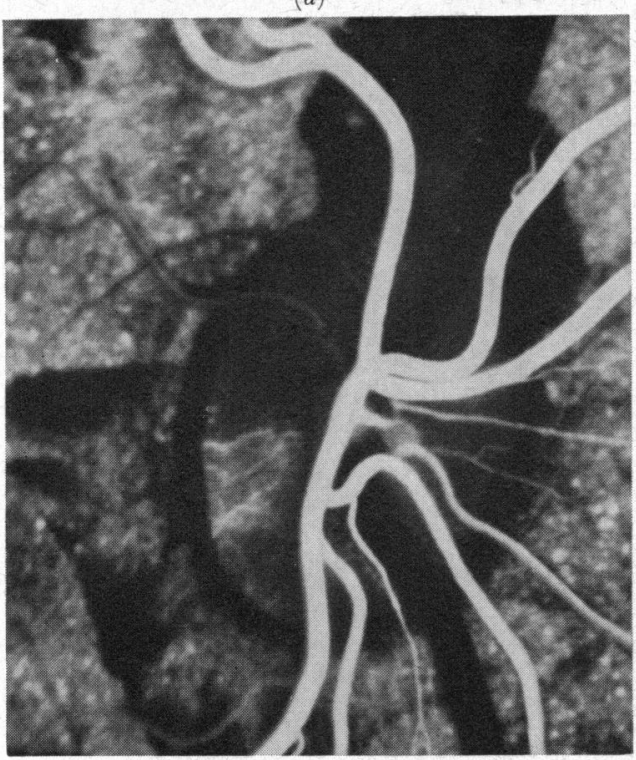

(b)

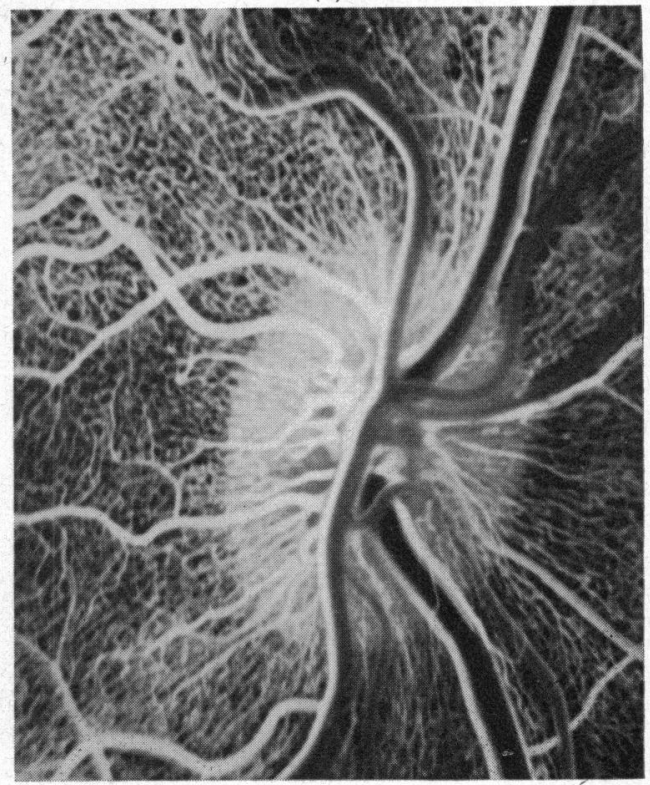

FIG. 8 Fluorescence angiograms of right eye of a cynomolgus monkey

(A) NORMAL EYE

(a) shows filling of the choroidal vessels and their contribution to the lower temporal quadrant of the disc and filling of the retinal arterioles but no filling of the retinal vascular bed. A ring of pigment at the disc margin is masking fluorescence

(b) during the arteriovenous phase, showing filling of the retinal vascular bed

taken in rapid sequence clearly showed the ciliary contribution to the disc during the prearterial phase; this was seen in the vast majority of the specimens in the temporal sector of the disc (Figs 7 and 8) and in some also on the nasal side (Fig. I Ia). Once the retinal capillaries of the surface layer had filled, the choroidal capillaries were completely masked by these (Fig. 8a,b). Thus it was impossible to assess the full contribution of the choroidal vessels to the optic disc. In order to assess the role played by the choroidal vessels in the blood supply of the optic disc, the central artery of the retina was experimentally blocked at its site of entry into the optic nerve. Fluorescence angiography in this preparation revealed the filling of the vessels in the whole temporal half of the optic disc and, during the later stages of the transit, the whole disc became fluorescent and the capillaries in the retina adjoining the temporal side of the disc were filled (Fig. $8 c-e$ ). At the end of the experiment, the disc was more or less as fluorescent as a disc with intact central retinal circulation (Fig. $8 f$ ). This, to my mind, leaves little doubt about the role of the ciliary circulation in the blood supply of the disc. The pictures of Kroll ( 1968 ) in a similar occlusion of the central artery of the retina in monkeys showed fluorescence of the optic disc with marked filling of the capillaries on the temporal side. The fluorescence picture in these instances resembled the central retinal artery occlusion seen in the patients mentioned above. Ernest and Potts (1968) concluded also that in rhesus monkeys the major source of vessels to the optic disc and lamina cribrosa was from the choroid and the posterior ciliary arteries.

From all these studies it can be concluded that the main source of blood supply to the optic nerve head is the ciliary circulation. 

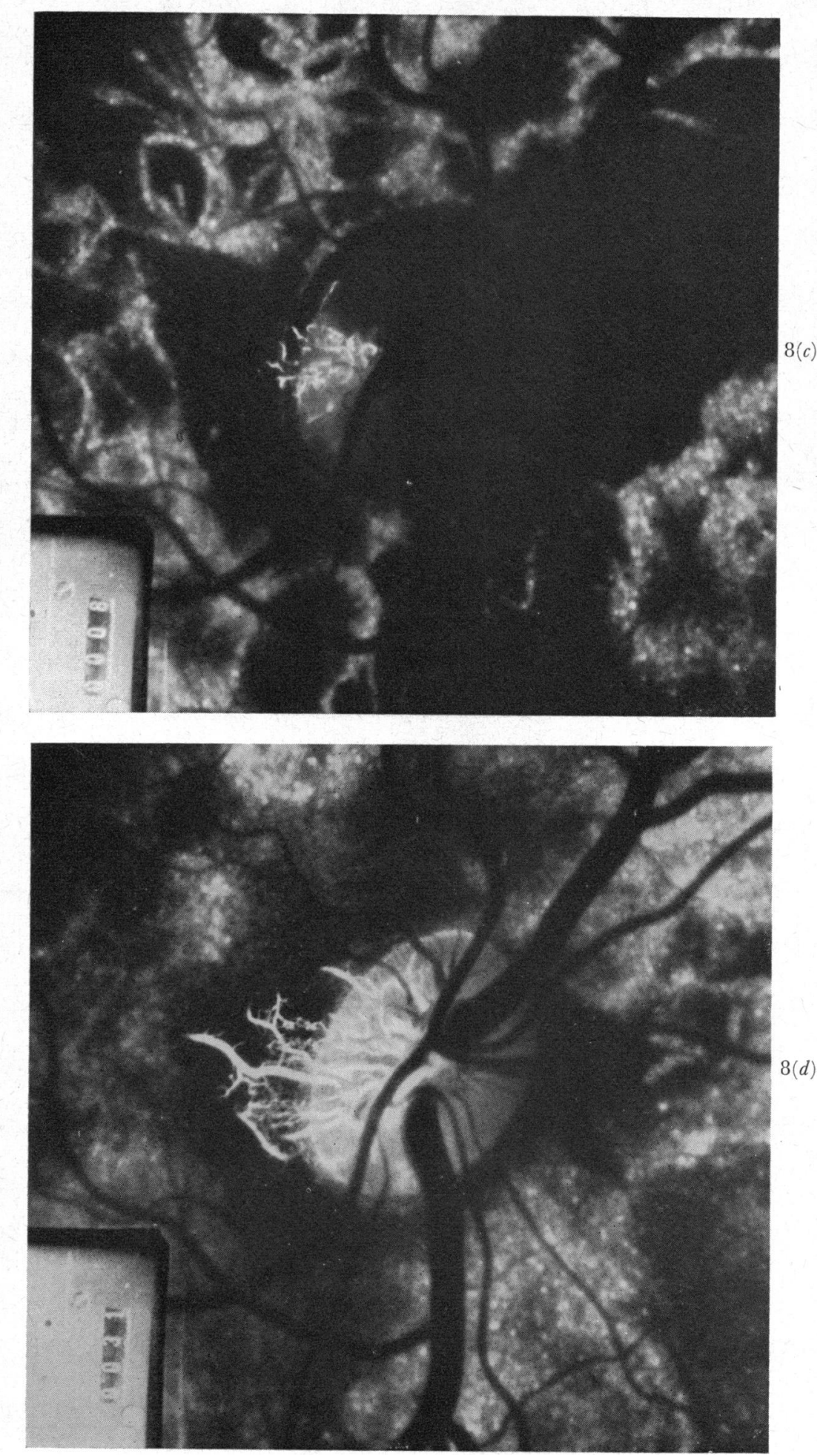

(B) AFTER EXYPERIMENTAL OCCLUSION OF THE CENTRAL RETINAL ARTERY IN THE SAME EYE $(c, d, e, f)$ show filling of choroidal vascular bed and its contribution to the disc with no filling of retinal vasculature 

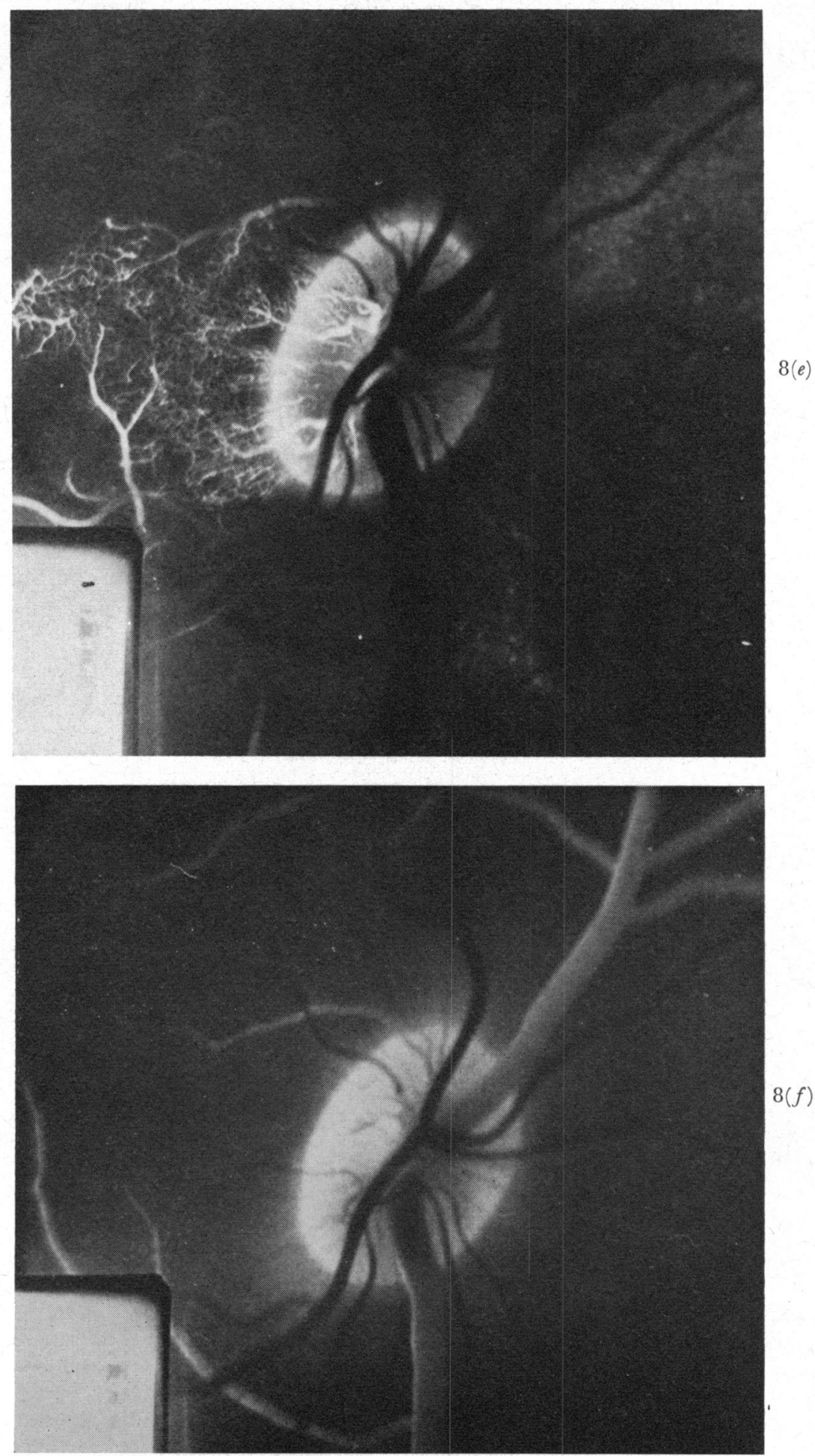

(c) is a phase comparable in timing to $(b)$

(e) shows filling of the temporal retina adjacent to the disc from the ciliary circulation of the disc

$(f)$ is a late phase showing marked fluorescence of the optic disc and some fluorescence of the retinal veins 


\section{Vascular anomalies}

The above pattern of the blood supply of the optic disc explains the presence of the two following vascular anomalies:

\section{GILIO-RETINAL ARTERY}

This is just an abnormal enlargement of one of the ciliary vessels in the temporal part of the disc (Fig. I). The subject of the cilio-retinal artery is discussed at length elsewhere (Hayreh, 1963b). The distribution of the cilio-retinal artery is mimicked nicely by the specimen from a cynomolgus monkey where the retina temporal to the optic disc filled after experimental central retinal artery occlusion (Fig. 8e, see page 729 ).

\section{RETINO-GILIARY VEIN}

Most authors call this the optico-ciliary vein; it connects the central retinal vein or its tributaries on the optic disc with the choroidal veins. It usually leaves the fundus at the margin of the optic disc (Fig. 9). Such a vessel has been described by many workers (Elschnig, 1888; Lawford, 1895; Coats, I9o6; Parsons, I906; Wybar, 1954; Duke-Elder, I96I ; Hoyt and Beeston, I966; Bonamour and others, I968; Shikano and Shimizu, I968; Sanders, 1969). Its formation can easily be understood from the pattern of the blood supply of the optic disc.

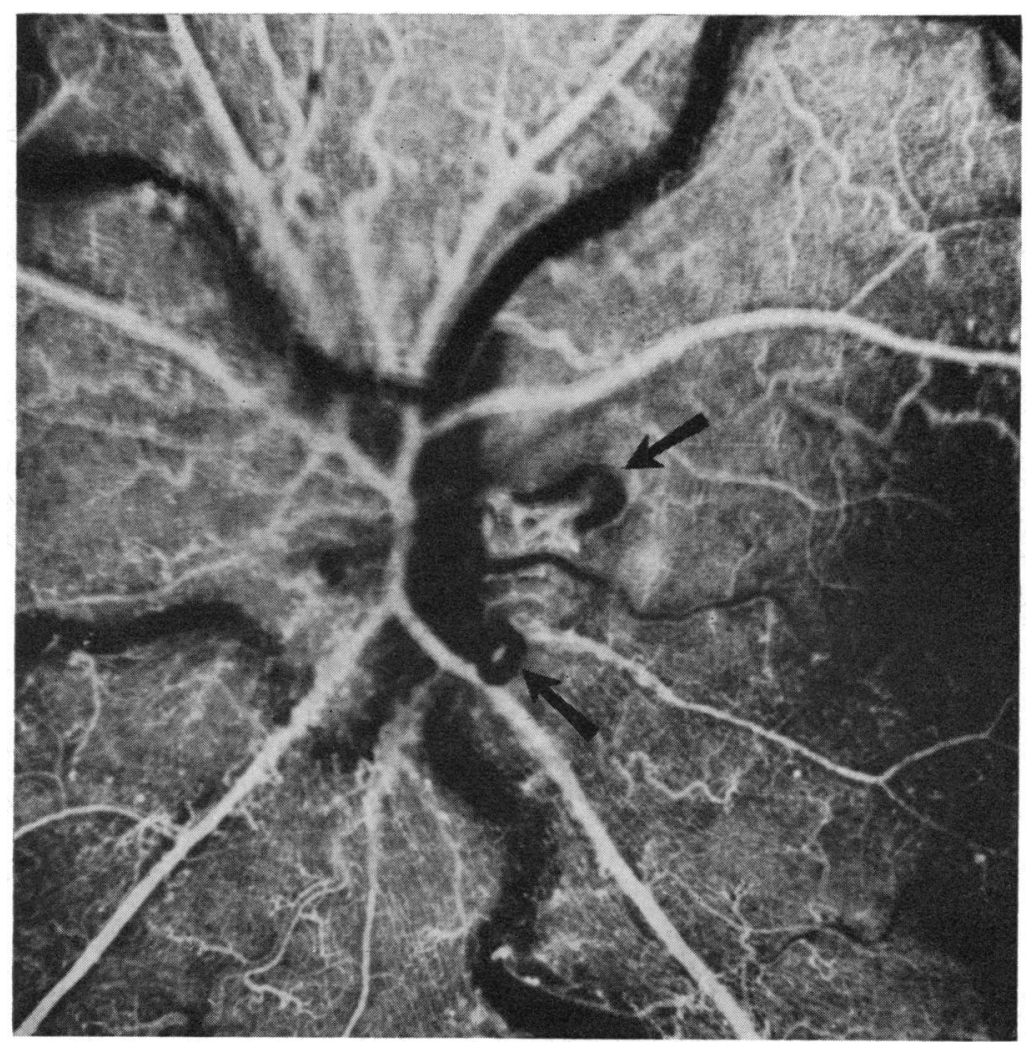

FIG. 9 Fluorescence angiograms during the arterial phase in a patient with chronic retinal venous obstruction. Arrows indicate retino-ciliary veins 


\section{PART II FLUORESGENCE OF THE NORMAL OPTIC DISG}

In normal eyes, fluorescence of the optic disc appears early with the onset of choroidal fluorescence before the central retinal artery fills with dye, i.e., during the prearterial phase. The prearterial filling of the disc is invariably prominent in the temporal sector. The fluorescence of the optic disc is usually maximal in the early arteriovenous phase of the retinal circulation, coincident or nearly so with the maximal background fluorescence of the fundus. The intensity of fluorescence of the normal optic disc and of the choroidal background during the different phases of the transit of the dye has been compared and is shown graphically in Fig. Ioa; the former is almost always more marked than the latter.

Basing my argument upon the human and experimental studies in monkeys, I feel that fluorescence of the normal optic disc seen during the transit of the dye represents a combined fluorescence of the surface layer and of the prelaminar region. The prelaminar fluorescence (i.e. of choroidal origin) contributes throughout, but maximally during the late venous phase of the transit; during the prearterial and the late phases it is the only source of disc fluorescence, in the latter because of the leakage of fluorescein from the choroidal capillaries. The surface layer fluorescence (i.e. of retinal origin) contributes maximally during the arterial and arteriovenous phases and not at all during the prearterial phase and the late phases.

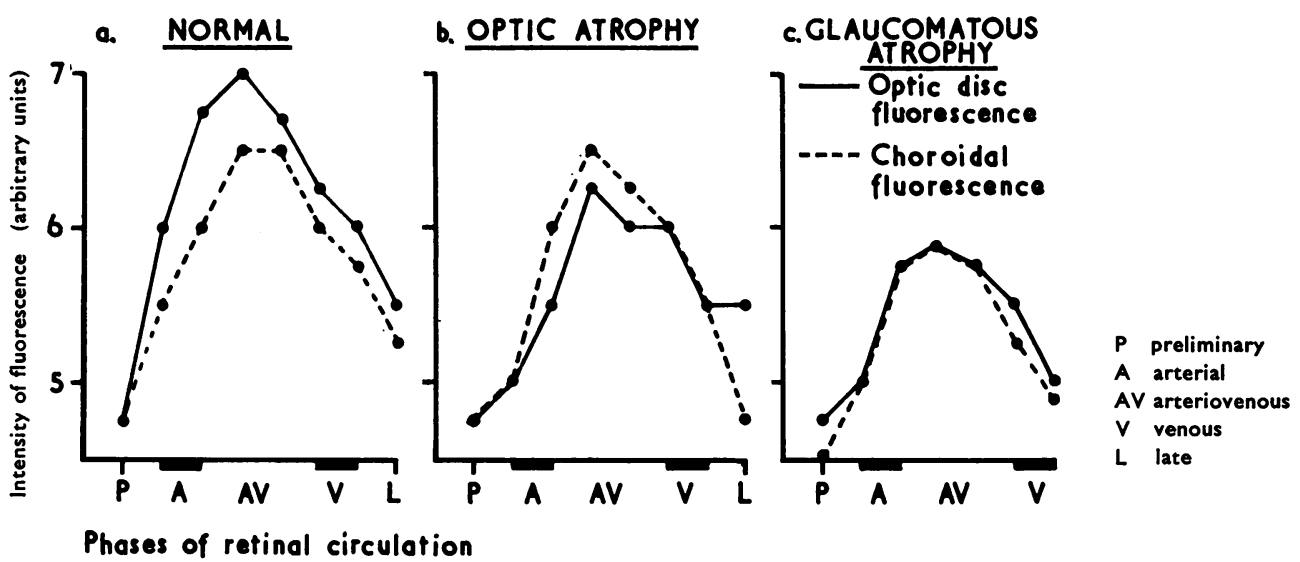

FIG. I O Graphs showing intensity of fluorescence of the optic disc and of the choroidal background of the fundus on fluorescence angiography in normal eye, optic atrophy, and glaucoma in man. The normal and optic atrophy graphs belong to two eyes of the same individual

\section{Redness and fluorescence of the optic disc}

Comparison of the intensity of fluorescence of the optic disc with its redness showed that the distribution of maximum fluorescence did not correspond with the distribution of maximum redness in forty out of 55 eyes studied, i.e. in 73 per cent. (Table I).

Table I Comparison of the distribution of maximum redness and fluorescence of the optic disc in 55 eyes

\begin{tabular}{|c|c|c|}
\hline Distribution & $\begin{array}{l}\text { Redness } \\
\text { (No. of cases) }\end{array}$ & $\begin{array}{l}\text { Fluorescence } \\
\text { (No. of cases) }\end{array}$ \\
\hline $\begin{array}{l}\text { Uniform all over } \\
\text { More marked on temporal part } \\
\text { More marked on nasal part }\end{array}$ & $\frac{22}{33}$ & $\begin{array}{l}33 \\
22 \\
-\end{array}$ \\
\hline
\end{tabular}


Out of 22 eyes with uniform redness, six showed more marked fluorescence on the temporal than on the nasal side. The temporal part of the optic disc was either as fluorescent as the nasal part or more so, but the redness of the optic disc was either uniform all over or more marked in the nasal than the temporal part. This lack of correspondence between the redness of the optic disc and its fluorescence is interesting but at the same time perplexing. I feel that the fluorescence of the optic disc mainly represents the vascularity of the superficial parts of the disc, while the redness of the disc is a three-dimensional view of its capillaries and those of the adjacent optic nerve. Since the optic nerve runs backwards and medially from the eyeball, we are perhaps seeing a much greater depth of the nerve nasally than temporally, and this may be responsible for the increased redness of the nasal part. From fluorescence angiography we know that the temporal part of the disc is usually more vascular than the nasal part.

It can be concluded from this that, in a normal optic disc, redness of the optic disc is not a true guide to its vascularity.

\section{PART III OPTIC ATROPHY, GLAUCOMA, AND OEDEMA OF THE OPTIC DISC}

Fluorescence angiographic studies have been carried out in optic atrophy, glaucoma and oedema of the optic disc in order to find out what vascular changes occur on the disc and to gain a better understanding of these conditions.

\section{Optic atrophy}

The fluorescence pattern of the optic disc was studied in fifteen patients with unilateral optic atrophy due to causes other than glaucoma (trauma in 5 , optic neuritis in 3 , vascular lesions in 5, cavernous sinus thrombosis in I, endocrine exophthalmos in I). The normal eye in each case acted as a control. It was discovered that fluorescence of the optic disc was less marked on the atrophic side than on the normal side (Fig. Iob, see previous page).

The reduced fluorescence of the atrophic disc has also been described by O'Day, Crock, Galbraith, Parel, and Wigley (1967), and Bonamour and others (1968). The view of O'Day and others (1967) that choroidal fluorescence of the disc is consistently absent in optic atrophy is not correct. This is because in patients with optic atrophy due to central retinal artery occlusion in the present series normal filling of the choroidal vessels could be seen (Fig. 4). My findings agree with those mentioned by Bonamour and others (1968) as regards the presence of two types of fluorescence pattern in optic atrophy:

(a) Generalized reduced fluorescence of the optic disc (Io cases), as also mentioned by O'Day and others (1967);

(b) Filling of the choroidal vessels in the disc (Fig. 4) (5 cases). The fluorescence of the disc was, however, less than normal.

Cases of the second type were mostly secondary to retinal lesions.

In normal eyes fluorescence of the optic disc was almost always more marked than the background fluorescence of the choroid (Fig. Ioa). In optic atrophy fluorescence of the $\stackrel{\infty}{+}$ optic disc was reduced (Fig. $10 b$ ). However, the choroidal fluorescence was unaffected. This led to an approximation of the fluorescence of the disc and the choroid. The $\stackrel{\mathbb{D}}{\mathbb{D}}$ impression given by this study was that with increased pallor of the disc there was a greater reduction in fluorescence of the disc, so that in cases with marked pallor the optic disc was 
less fluorescent than the choroid (Table II). This finding is significant when compared with the pattern seen in glaucomatous optic atrophy (Fig. Ioc). In the latter there is a reduction in fluorescence of both optic disc and choroid in the vast majority of cases.

Table II Comparison of distribution of pallor and fluorescence of the optic disc

\begin{tabular}{lll}
\hline Distribution & $\begin{array}{l}\text { Pallor of the optic } \\
\text { disc } \\
\text { (No. of cases) }\end{array}$ & $\begin{array}{l}\text { Fluorescence of the } \\
\text { optic disc } \\
\text { (No. of cases) }\end{array}$ \\
\cline { 2 - 3 } & Io & 10 \\
Uniform & $4^{*}$ & $5^{*}$ \\
Nasal more than temporal & I & 0
\end{tabular}

*One case was common to both groups

CASES OF OPTIC ATROPHY WITH RETINITIS PIGMENTOSA

These have also been studied by fluorescence angiography. The vessels of choroidal origin in the prelaminar region of the disc were well outlined and no significant abnormality was seen in them (Fig. 6). The retinal arterioles, however, filled after a significantly prolonged interval after filling of the choroidal vessels, and this interval was many times the normal time-gap between the two circulations. The retinal capillaries in the surface layer of the disc were not seen clearly. The entire picture very much resembled that seen in cases with partial central retinal artery occlusion. The waxy colour of the disc in retinitis pigmentosa is presumably due to the normal vessels of the prelaminar region being seen through the surface layer, the latter having lost its capillary plexus and being affected by gliosis.

\section{Glaucoma}

Hayreh and Walker ( 1967 ) reported in detail the fluorescence pattern of the optic disc and its relationship to cupping of the optic disc and field defects. It was found that there was a reduction in fluorescence of the optic disc in a large number of patients with significant changes at the optic disc and visual field defects. This suggested permanent interference with the blood supply of the optic disc in glaucoma.

A retrospective study of the relationship between the fluorescence of the optic disc and choroidal background has been carried out on this series, and on four additional eyes, i.e. on a total of 37 eyes. In the majority of cases the fluorescence of the optic disc and choroid tended to approximate to one another (Fig. IOc): the more the cupping and the field defects, the less the difference between the two. However, the general pattern in these was similar to that in the normal optic disc. In two eyes the choroidal fluorescence was more than the optic disc fluorescence; both had marked cupping of the optic disc. In none of these cases could fine capillaries on the optic disc and retina be outlined even in the best fluorescence angiograms. The inability to visualize capillaries by this technique in these patients may indicate a generalized reduction of capillaries in these eyes. This would confirm the suggestion that there is a generalized reduction of the capillary network in the eye in glaucoma (Elschnig, 1928; Cristini, I95 I François and Neetens, 1964, 1966).

The experimental studies in monkeys showing the effects of raised intraocular pressure on the choroidal contribution to the blood supply of the optic disc have been described at length by Hayreh and Perkins (1968, 1969). These showed that the choroidal contribution to the optic disc is most susceptible to the raised intraocular pressure and becomes 

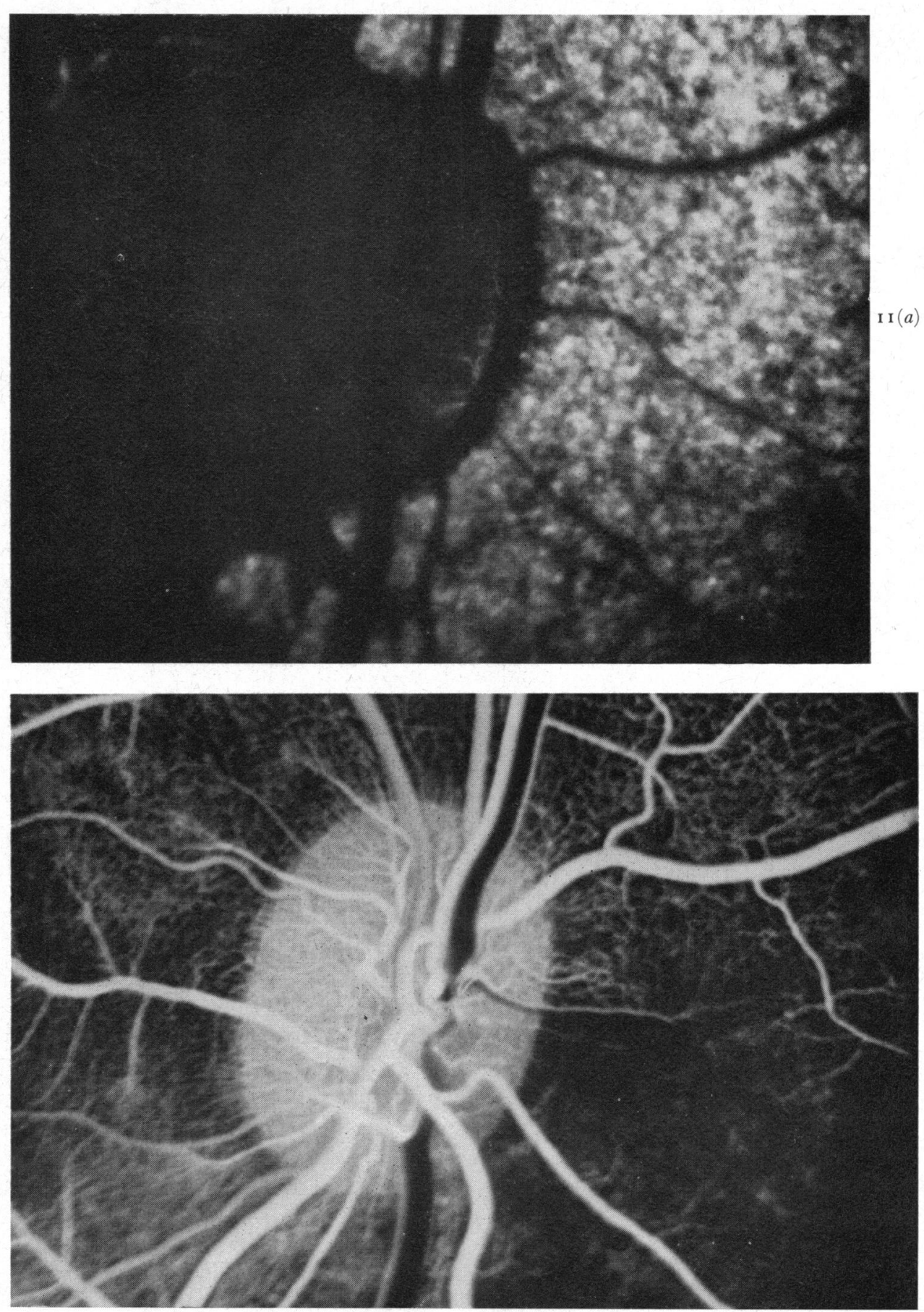

FIG. I I Fluorescence angiograms of right eye of a cynomolgus monkey

(A) AT NORMAL INTRAOCULAR PRESSURE

(a) during preretinal-arterial phase, showing filling of the choroid and choroidal contribution to the nasal part of the disc. A ring of pigment at the disc margin is masking fluorescence

(b) during early arteriovenous phase, with a normal spatial filling defect (Hayreh, 1969) in retinal vascular bed in inferior nasal quadrant 

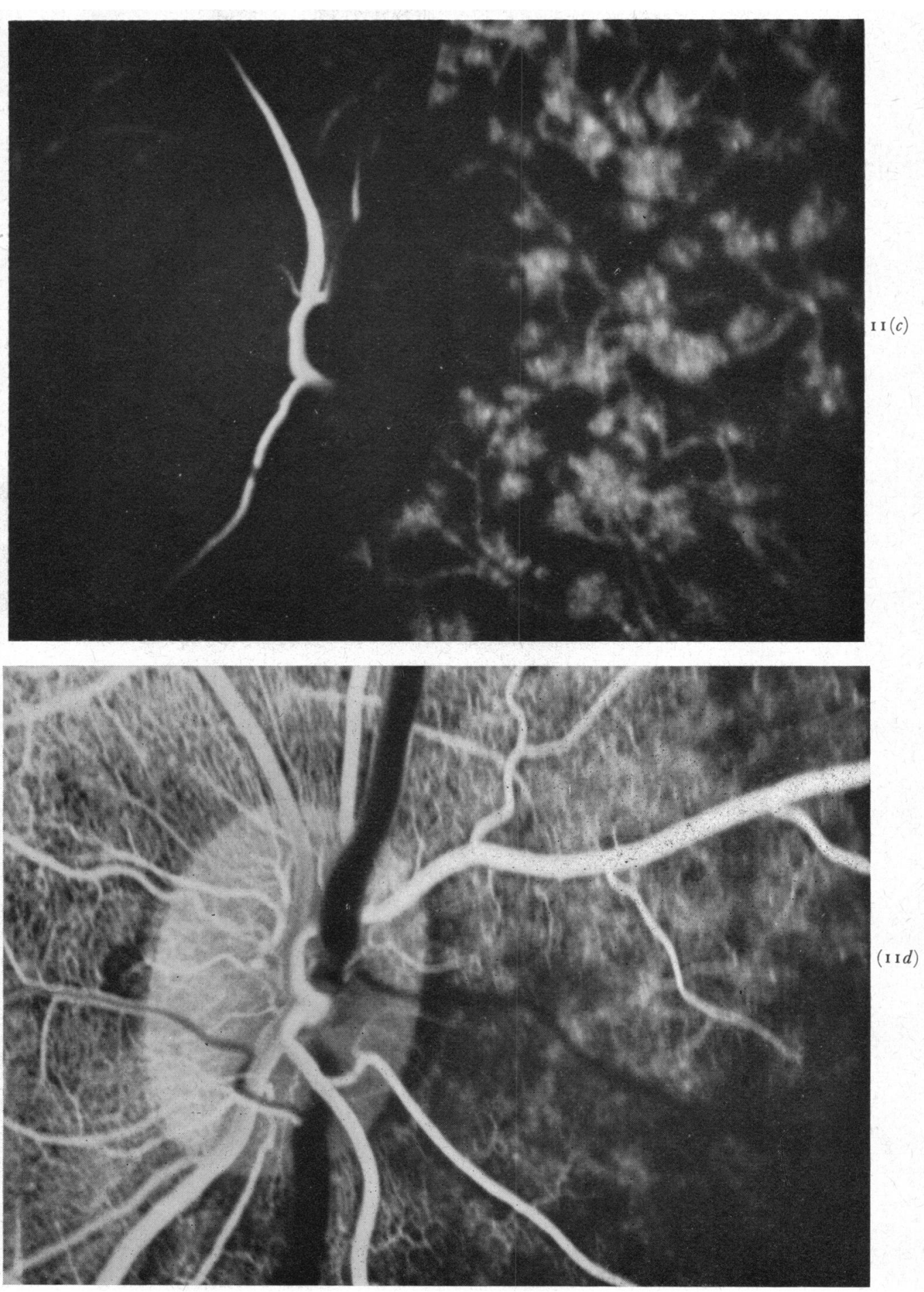

(B) AT $70 \mathrm{~mm}$. Hg intraocular PREsSURe

(c) during the early arterial phase, showing poor filling of the choroid and no filling of vessels of choroidal origin in the disc

(d) during early arteriovenous phase comparable to $(b)$ in timing of the transit of the dye 
obliterated (Figs i $1 a-d$, pp.734-5 and 12). The peripapillary choroid is either equally or slightly less susceptible to obliteration by the raised intraocular pressure, and this has also been seen by other workers (Gitter, Blumenthal, Galin, and Best, I969, in man; Ernest and Potts, 1968, and David, I969, in monkeys). In the peripapillary choroid, the obliteration was usually more marked in its superior and inferior parts, less marked on the temporal side and least marked on the nasal side of the disc. The obliteration of the peripapillary choroid itself would in turn involve the supply to the prelaminar region of the disc as well.

In histopathological studies on monkey eyes with experimental glaucoma, Kalvin, Hamasaki, and Gass (1966) have shown a reduction in the number of capillaries in the optic disc, most marked on the temporal side, in addition to that in the posterior pole of the eye. Cristini ( $195 \mathrm{I}$ ), in his study of forty glaucomatous eyes, observed particularly severe reduction of capillaries in the lamina cribrosa and in some cases in the peripapillary choroid also. François and Neetens (1964, 1966) have also observed the same.

The rest of the choroidal circulation is also very susceptible to raised intraocular pressure, although less so than the peripapillary choroid and the choroidal supply to the
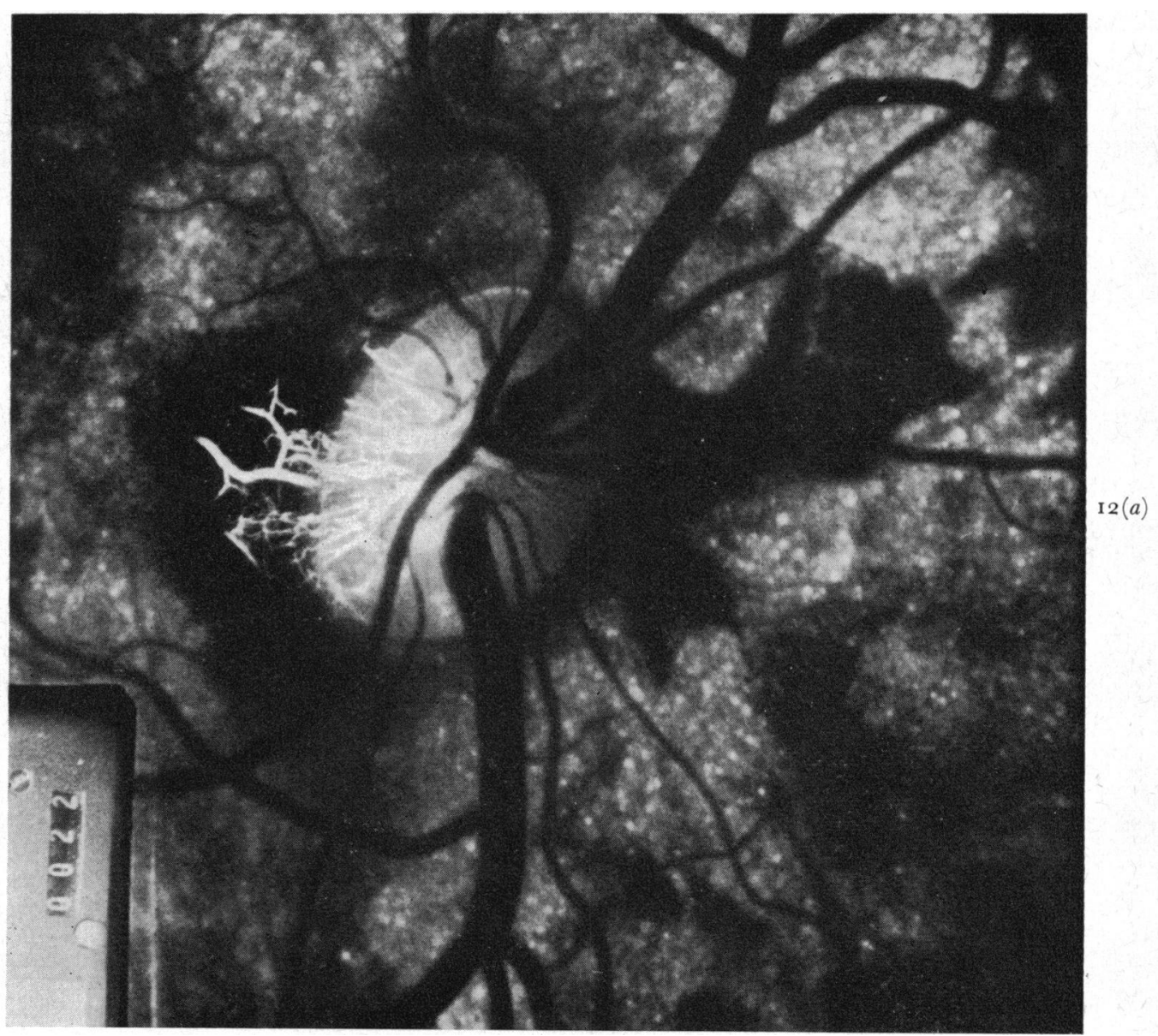

FIG. I 2 Fluorescence angiograms showing the effects of raised intraocular pressure on the eye of a cynomolgus monkey (shown in Fig. 8 after occlusion of the central retinal artery)
(a) normal
(b) $70 \mathrm{~mm} . \mathrm{Hg}$
(c) $30 \mathrm{~mm} . \mathrm{Hg}$
$(a),(b)$, and $(c)$ represent the same phase of the transit of the dye at the three pressures 
disc (Fig. I I $c, 12 b, c$ ). In the choroid it was most marked in the watershed areas where the territories of distribution of the medial and lateral posterior ciliary arteries meet (Hayreh and Perkins, I969). The anatomical pattern of the posterior ciliary arteries is described in detail elsewhere (Hayreh, 1962a).

Ernest and Potts (1968), in similar experiments in rhesus monkeys, found no filling of the vessels in the optic disc, the lamina cribrosa, and for $\mathrm{I}-2 \mathrm{~mm}$. posterior to the lamina cribrosa in the optic nerve. Hamasaki and Fujino (1967), in experimental glaucoma in owl monkeys, noted a deficiency in the filling of the capillaries of the optic nerve which was greater in the temporal than in the nasal half.

We have found that the retinal circulation, however, is not significantly affected in acute elevation of the intraocular pressure (Fig. I I $d$ ) (Hayreh and Perkins, I968, I969). This contradicts the views of Henkind (1967a, b), Alterman and Henkind (1968), and Kornzweig, Eliasoph, and Feldstein (1968). The filling defect seen by Henkind in retinal vasculature with experimentally raised intraocular pressure in the cat seems to be an example of the normal spatial variation in the filling of the retinal vasculature which has been described elsewhere (Hayreh, I969; see also Fig. I I $b$ ).

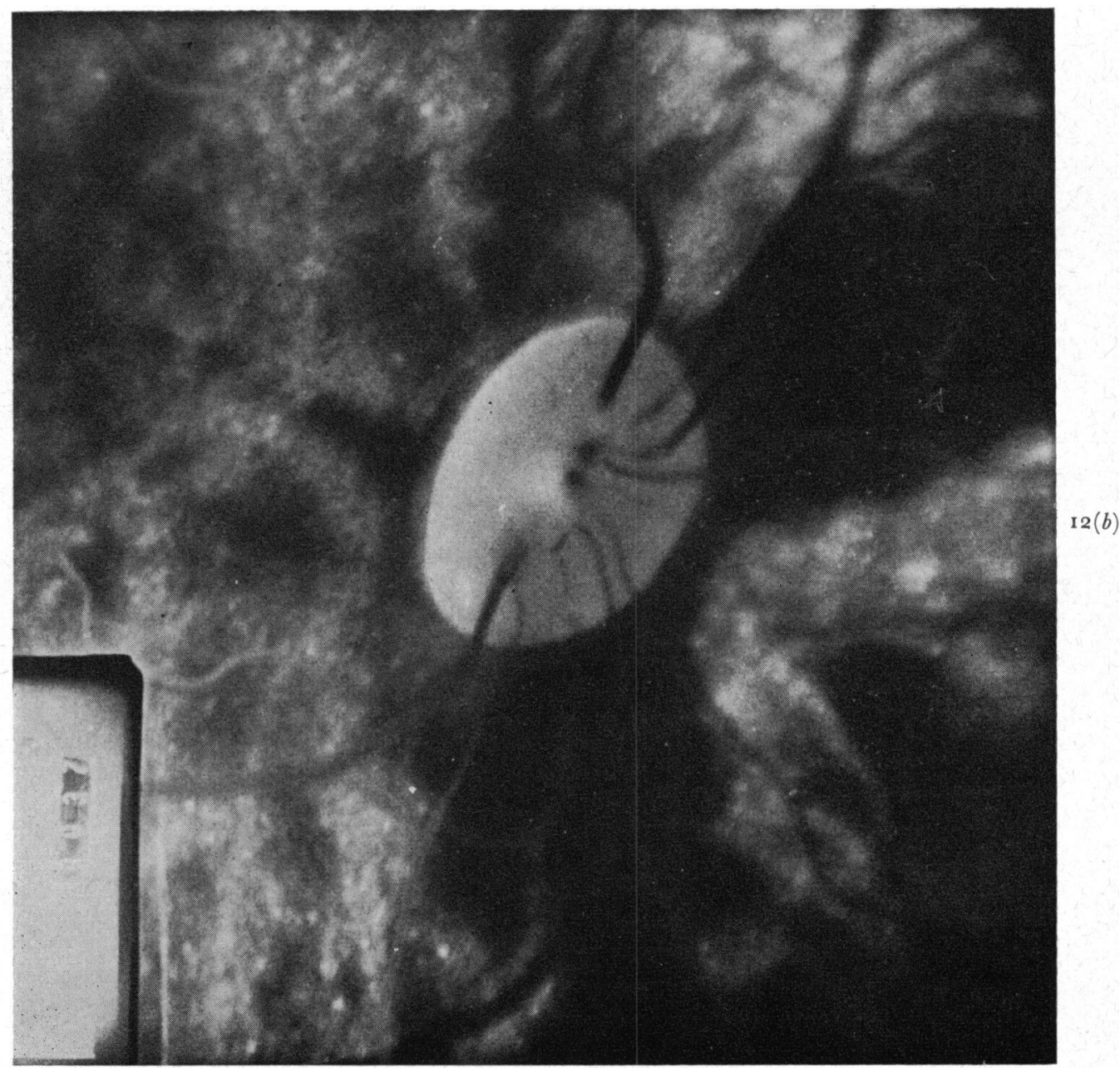




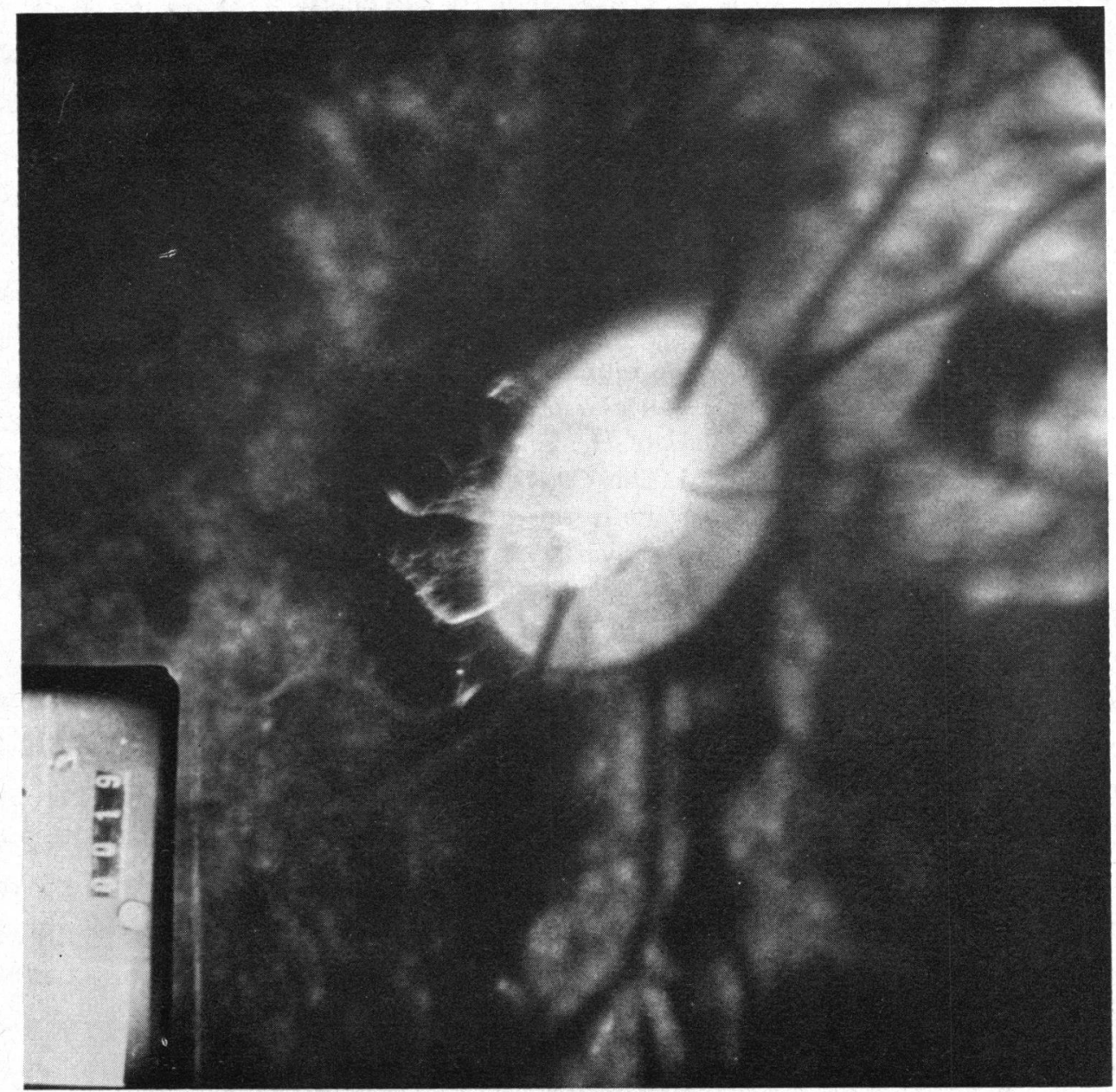

Kornzweig and others (1968) have shown a selective atrophy of the radial peripapillary capillaries of the retina in patients who had raised intraocular pressure, most of them without optic disc changes, and in none were visual field records available. Capillary $\stackrel{\rho}{\rho}$ atrophy, instead of being the cause of nerve fibre degeneration, can be secondary to nerve

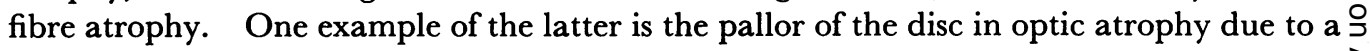
distant lesion of the optic nerve.

The fact that the choroidal contribution to the blood supply of the optic disc and the peripapillary choroid is most susceptible to obliteration by the elevated intraocular pressure would go a long way. towards explaining the pathogenesis of the nerve fibre bundle defects, cupping of the optic disc, and cavernous degeneration of the optic nerve in glaucoma.

It seems that the obliteration of the centripetal choroidal vessels to the disc causes the nerve fibre bundle defects in glaucoma by involving nerve fibres in the area of their supply in the disc. If, for example, the vessels in the upper part of the disc were involved (Fig. $\stackrel{\oplus}{\stackrel{D}{+}}$ I3, opposite), these would involve the nerve fibres in their area of supply and thus produce $\frac{0}{7}$ an inferior arcuate scotoma. A similar effect would be produced if a sector of the peri- $\frac{\vec{D}}{\Phi}$ papillary choroid were obliterated, because it would in turn involve the centripetal vessels $\frac{\rho}{\oplus}$ in the corresponding sector of the disc. 


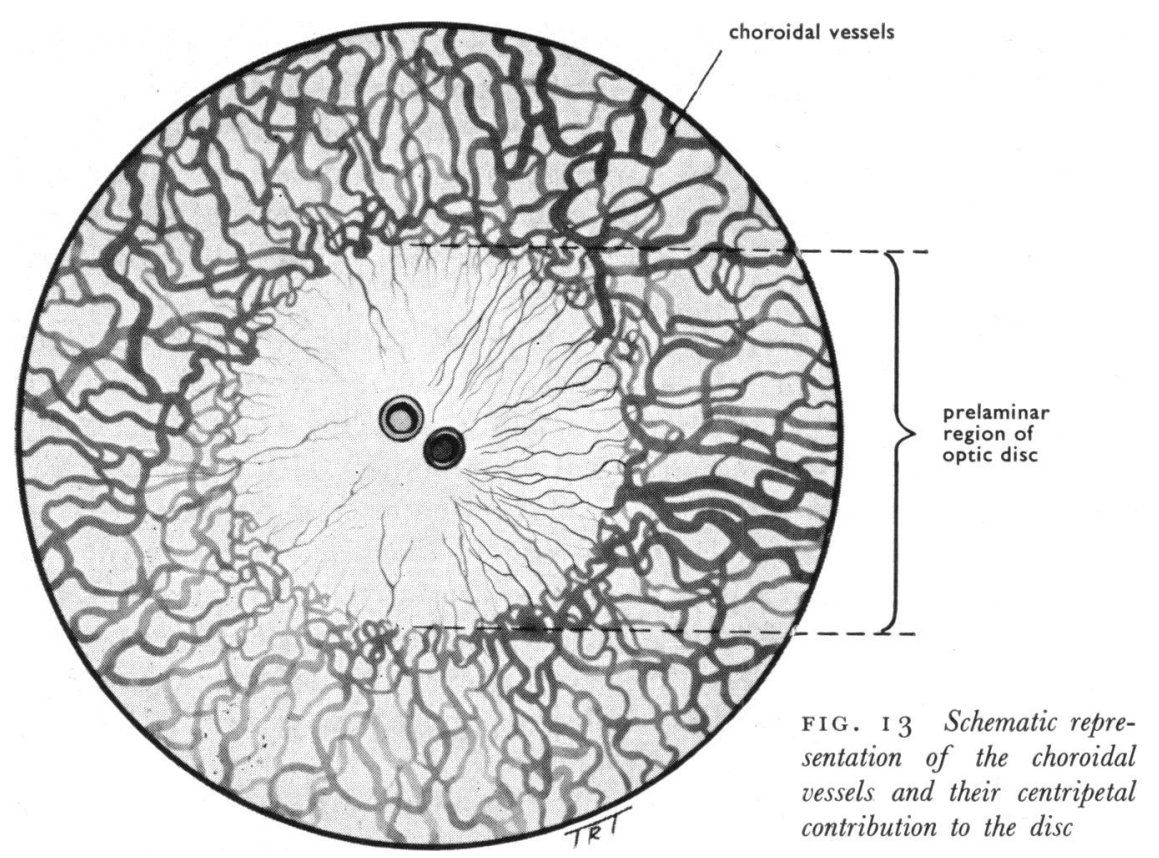

At this stage of our knowledge, however, it is not possible to state definitely the reason for the characteristic distribution of the various nerve fibre bundle defects in glaucoma. I believe it to be due to a greater susceptibility to obliteration of the centripetal vessels of the disc or the peripapillary choroid in certain sectors than in others. Since the superior and inferior peripapillary choroid is usually more susceptible to obliteration than the temporal part, on elevation of the intraocular pressure, and the nasal part is the least susceptible of all, this may determine the distribution of the field defects. The fact that the area of the disc containing the papillo-macular bundle is the most vascular may explain why it is involved last of all in most cases of glaucoma.

From these studies it could be postulated that the site of the lesion in nerve fibre bundle defects in glaucoma lies in the disc and not in the retina, and that this is due to the involvement of the choroidal supply to the disc.

The question now arises why the choroidal supply to the disc and the peripapillary choroid shows maximum susceptibility to obliteration on raising the intraocular pressure. It is not possible to give a definite explanation for this well-established phenomenon. One can only speculate. The fine centripetal branches in the prelaminar part of the optic disc (Fig. I) may be sandwiched between the raised intraocular pressure and the rigid lamina cribrosa, so that their blood is squeezed out into the adjacent choroid. Thus the relationship between blood pressure in these centripetal disc vessels and the intraocular pressure determines the state of patency of these vessels and a critical balance exists; lowering of the blood pressure or elevation of the intraocular pressure would have a similar effect. Such a phenomenon was observed by Harrington (1959) in patients with hypertension. It seems that the area of the peripapillary choroid involved lies between the margin of the disc and the site of entry of the posterior ciliary arteries into the eyeball. Since the main branches of the posterior ciliary arteries run forwards, the peripapillary choroid is presumably formed by small recurrent branches from these vessels, and this may form a low pressure system as compared with the main choroid. These features of the 
peripapillary choroidal vessels may render them more prone to obliteration and involvement by raised intraocular pressure. This tendency would be further increased by the presence of the recurrent pial branches to the retro-ocular part of the optic nerve from this part of the choroid (Fig. I), which would prevent a compensatory rise in blood pressure in the peripapillary choroid because the pial branches are not subjected to the raised intraocular pressure. The peripapillary choroid in turn would involve the disc vessels arising from it.

The response of the choroidal vessels in the disc to raised intraocular pressure is totally different from that of the retinal vessels. Unlike the choroidal vessels in the disc, the retinal circulation is a closed circulation, with one feeding trunk (the central retinal artery) and one exit channel (the central retinal vein), both situated on the optic disc. Elevation of the intraocular pressure would produce a corresponding rise in the pressure in the central retinal vein, which in turn would produce back pressure, thus preventing the obliteration of the retinal capillaries. In contrast to this, the choroidal contribution to the optic disc is not a closed circulation but a very minor offshoot of the vast choroidal vascular bed. I feel that this difference in the two types of circulation to the disc is most probably responsible for the closure of the choroidal supply, but not of the retinal supply, on elevation of the intraocular pressure.

In patients with glaucoma, peripapillary choroidal atrophy is much more common than in normal individuals. This may be responsible for the enlarged blind spot in such cases. The choriocapillaris would be obliterated before the bigger vessels; this in turn would lead to degeneration of the pigment epithelium and of the overlying visual cells, producing an enlarged blind spot with a white ring round the optic disc. It should be stressed that the presence of a white peripapillary area seen ophthalmoscopically in a fundus does not always mean that the underlying large choroidal peripapillary vessels are absent, but is due mainly to the unmasking of Bruch's membrane, the large peripapillary vessels being intact. The bigger choroidal vessels may still be seen in this region on fluorescence angiography.

CAVERNOUS DEGENERATION OF THE RETROBULBAR PART OF THE OPTIC NERVE

The problem of association of cavernous degeneration in the retrobulbar part of the optic nerve with glaucoma has baffled everybody since its first description by Schnabel (1892). I feel it is not difficult to explain the mechanism if one considers the normal blood supply of that part of the optic nerve. A detailed account of the blood supply of the optic nerve has been given elsewhere (Hayreh, I962b, I963a, c). Briefly, the retrobulbar part of the optic nerve, the portion containing the central retinal vessels, has a centrifugal and a centripetal vascular system (Fig. I). The centrifugal system is present in 75 per cent. of cases and is formed by the intraneural branches of the central retinal artery. The centripetal vascular system is present in roo per cent. and is formed by the pial branches. The pial branches supplying this part arise mostly from the peripapillary choroid and the circle of Zinn. Since the circle of Zinn is not a common finding and its supply is usually taken over by branches from the ciliary arteries, it may play no part, or only a minor one, in the blood supply of the retrobulbar part of the optic nerve in the majority of cases. The peripapillary choroid also supplies the prelaminar part of the optic disc, as already mentioned. Our experimental studies (Hayreh and Perkins, 1968, 1969) and those of David (1969) and Gitter and others ( 1969 ) have shown that the vessels of the peripapillary choroid are most susceptible to obliteration by a raised intraocular pressure. Cristini (195I) has shown histopathologically a particularly severe reduction of vessels in the peripapillary choroid and in the lamina cribrosa. François and Neetens (1964, 1966) have made somewhat similar 
observations and have also demonstrated a fragmentation of the circle of Zinn which mostly ends in these cases in a cul-de-sac.

The peripapillary choroid supplies the optic disc and the retrobulbar part of the optic nerve (Fig. I). Therefore all these changes in the peripapillary choroidal vessels would involve not only the vessels in the prelaminar part of the optic disc but also the pial branches arising from them and going to the retrobulbar part of the optic nerve. This would result in progressive ischaemia and ultimately cavernous degeneration of the retrobulbar part of the optic nerve. Wolff (1947) also stated that Schnabel's cavernous atrophy was an expression of the effect on the optic nerve of a progressive diminution in its blood supply; the more highly differentiated nerve fibres, therefore, disappear first. The ischaemia of the optic nerve head would lead to nerve fibre bundle defects and cupping. It seems that a similar peripapillary choroidal atrophy due to causes other than glaucoma could lead to cavernous atrophy, e.g. myopia and pseudoglaucoma.

The contribution of the choroidal vessels to the blood supply of the optic disc, and to the retrobulbar part of the optic nerve (Hayreh, I962b, 1963a, c, I966; Hayreh and Perkins, 1968), experimental evidence of their being affected by raised intraocular pressure in monkeys (Hayreh and Perkins, 1968, 1969; Ernest and Potts, 1968; David, 1969) and in man (Gitter and others, 1969), and histopathological evidence in the literature on the subject (Cristini, I95I ; François and Neetens, I964, I966; Kalvin and others, I966) seem to form a firm basis for the hypothesis that in glaucoma the primary factor responsible for the visual field defects, optic disc changes, and cavernous degeneration in the optic nerve is the involvement of the choroidal vasculature, especially its peripapillary part and its contribution to the optic disc.

The peripapillary choroid seems to be most susceptible not only to raised intraocular pressure but also to degenerative and atrophic choroidal lesions because many forms of choroidal degeneration start or are situated in this region.

\section{Oedema of the optic disc}

The presertce of capillary dilatation, aneurysms, and haemorrhages on the optic disc and in the adjacent retina in oedema of the optic disc have been well documented by a large number of authors (Miller, Sanders, and ffytche, 1965; Dollery, Mailer, and Hodge, 1965; Hayreh, I968; and many others) in addition to fluorescence of the optic disc (Fig. I4, overleaf). In a series of fifteen cases of retrobulbar neuritis with ophthalmoscopically normal optic discs, fluorescence angiography revealed fluorescence of the disc but no other change (Fig. 15, overleaf). The findings of Rosen and Ashworth (1968) were similar. This indicates that oedema of the optic disc precedes the capillary dilatation and other vascular changes commonly associated with it. I believe that the retinal vascular changes are secondary to the oedema and not the cause of it. The oedema compresses the capillaries and other thin-walled fine vessels in the prelaminar region and on the surface of the disc (Fig. I). Most of these vessels on the surface of the disc are of a venous nature and many of them are the terminal portions of the long radial peripapillary capillary network, running along the superior and inferior temporal retinal vessels and draining into the veins on the disc. Compression of these vessels at the optic disc produces stasis in the territory drained by them and thus leads to their dilatation and the formation of aneurysms. This would explain the extension of these changes up and down the retinal wessels in the zone of the radial peripapillary capillary network and also in the retina adjoining the optic disc. In cases of retrobulbar neuritis, where there was oedema of only a part of the optic disc, the vascular changes were limited to that sector only. Thus it is the presence and distribution of the oedema of the disc which determines the vascular changes. 


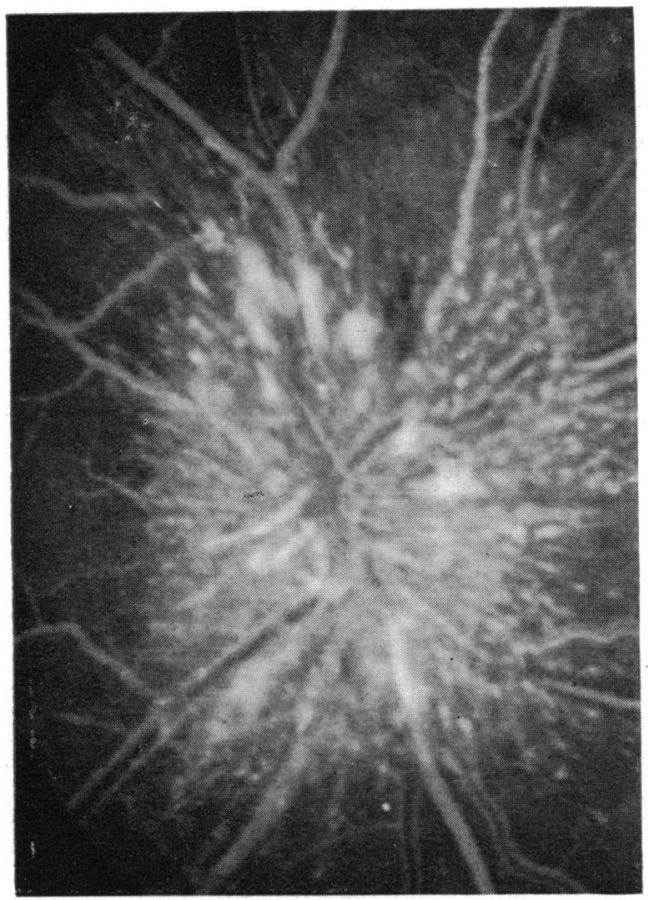

FIG. I 4 Fluorescence angiogram in a patient with oedema of the optic disc during the arteriovenous phase

(a)

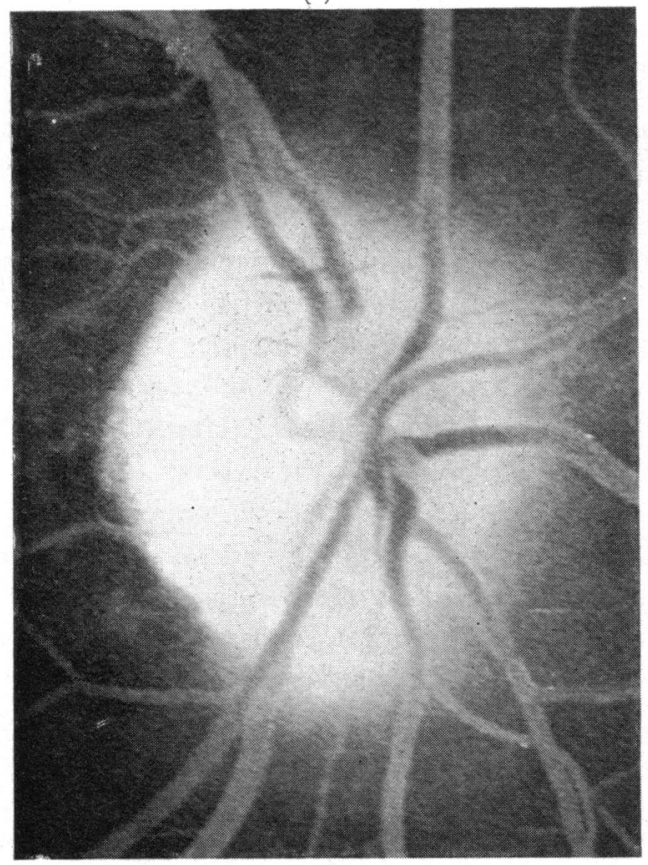

(b)

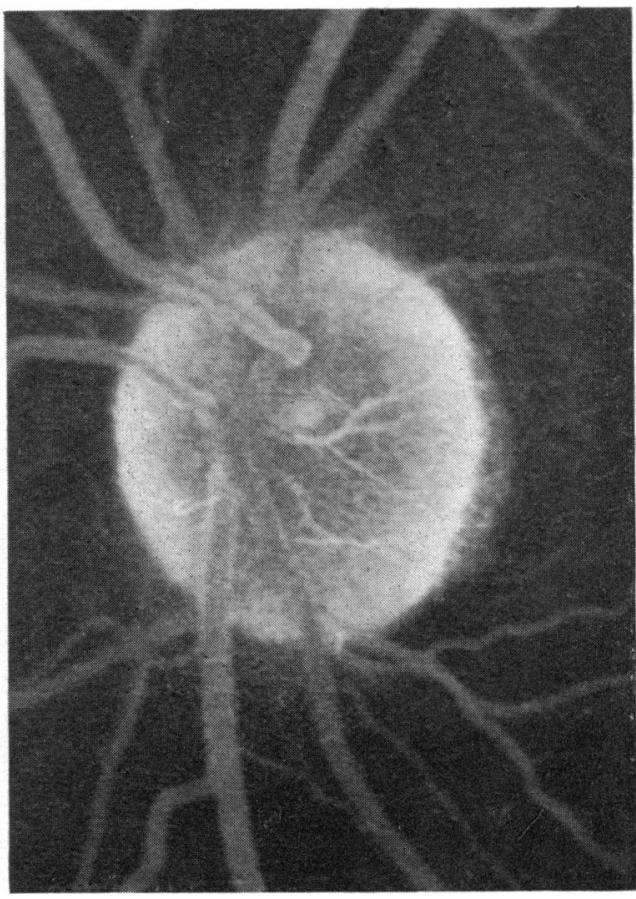

FIG. I 5 Fluorescence angiograms in a patient with retrobulbar neuritis of right eye with normal optic disc on $\frac{\mathbb{Q}}{\Omega}$ ophthalmoscopy. Note difference in fluorescence between right disc (a) and normal left disc (b) during late phase 
The fact that the retinal vascular changes are secondary to the oedema is important in the proper understanding of the pathogenesis of oedema of the disc. This supports my previous experimental work on the subject (Hayreh, 1965, 1968), where interference with the circulation of the central retinal vein by raised intracranial pressure was ruled out as the causative factor. The subject has been discussed in detail elsewhere (Hayreh, 1965, 1968).

Recent findings have suggested that there is no one single explanation for the pathogenesis of oedema of the optic disc of different origins. The oedema in different conditions is of different types, and is caused by different mechanisms. Thus a single blanket explanation for the process is likely to lead to confusion. This will be evident to some extent from the following comments.

In oedema of the optic disc due to intracranial hypertension, the oedema of the prelaminar region appears to compress the venous channels (Fig. I), and this leads to dilatation and tortuosity of the prelaminar vessels. The prelaminar vessels, being of choroidal origin, leak profusely and lead to the marked fluorescence of the optic disc in cases of marked oedema of the optic disc. Even in a normal disc, the small degree of delayed fluorescence of the disc is due solely to the leakage of fluorescein from the choroidal vessels in the disc. Normally the retinal capillaries do not contribute to the delayed fluorescence of the disc. Even in cases of oedema of the optic disc the dilated retinal capillaries seem to contribute little to the phenomenon of disc fluorescence. The presence of dilated and tortuous prelaminar vessels in the disc is well seen in stereoscopic pictures of the disc and also in subjects with chronic oedema of the optic disc (Fig. 6). The same thing is shown histologically by Henkind ( 1969 ) in his sections of oedema of the optic disc (Fig. 16, overleaf).

It is well known that in cases with central retinal vein occlusion, oedema of the disc is not as marked as in cases with raised intracranial pressure. In cases with intracranial hypertension, as mentioned above, the oedema of the prelaminar region most probably compresses all the venous channels in this area leading to back pressure, dilatation, tortuosity, more oedema, and thus to a vicious circle which produces marked oedema of the disc. In cases of chronic oedema of the optic disc, there is proliferation of the vessels in the prelaminar region in addition to dilatation and tortuosity (Fig. 6). On the other hand, in central retinal vein occlusion situated behind the region of the lamina cribrosa, the venous channels of the prelaminar region act as collateral channels to drain away the blood to the choroid and remain patent all along, so that there is no significant oedema in such cases. This would also explain the development of retino-ciliary veins.

The fact that leakage from the dilated prelaminar vessels is marked may be one of the factors in the localization of oedema to the optic disc, in addition to the looseness of this area.

In cases with ocular hypotension, the fall in the intraocular pressure presumably leads to effusion from the choroidal capillaries in the prelaminar region-a phenomenon similar to choroidal detachment-which collects in the loose glial tissue of the prelaminar region. This, however, does not become marked because the rise of tissue pressure in the prelaminar region would act as an opposing force to maintain a low degree of oedema of tissues in the disc.

Oedema of the optic disc in uveitis is most probably due to two factors, acting either singly or together. When ocular hypotension is associated with uveitis, it may produce oedema of the disc, the mechanism of which is discussed above. The other factor is most probably the involvement of the ciliary vessels to the disc as a part of the posterior uveitis, which produces an increased capillary permeability of these vessels at the disc and oedema of the loose tissue of the optic disc. 

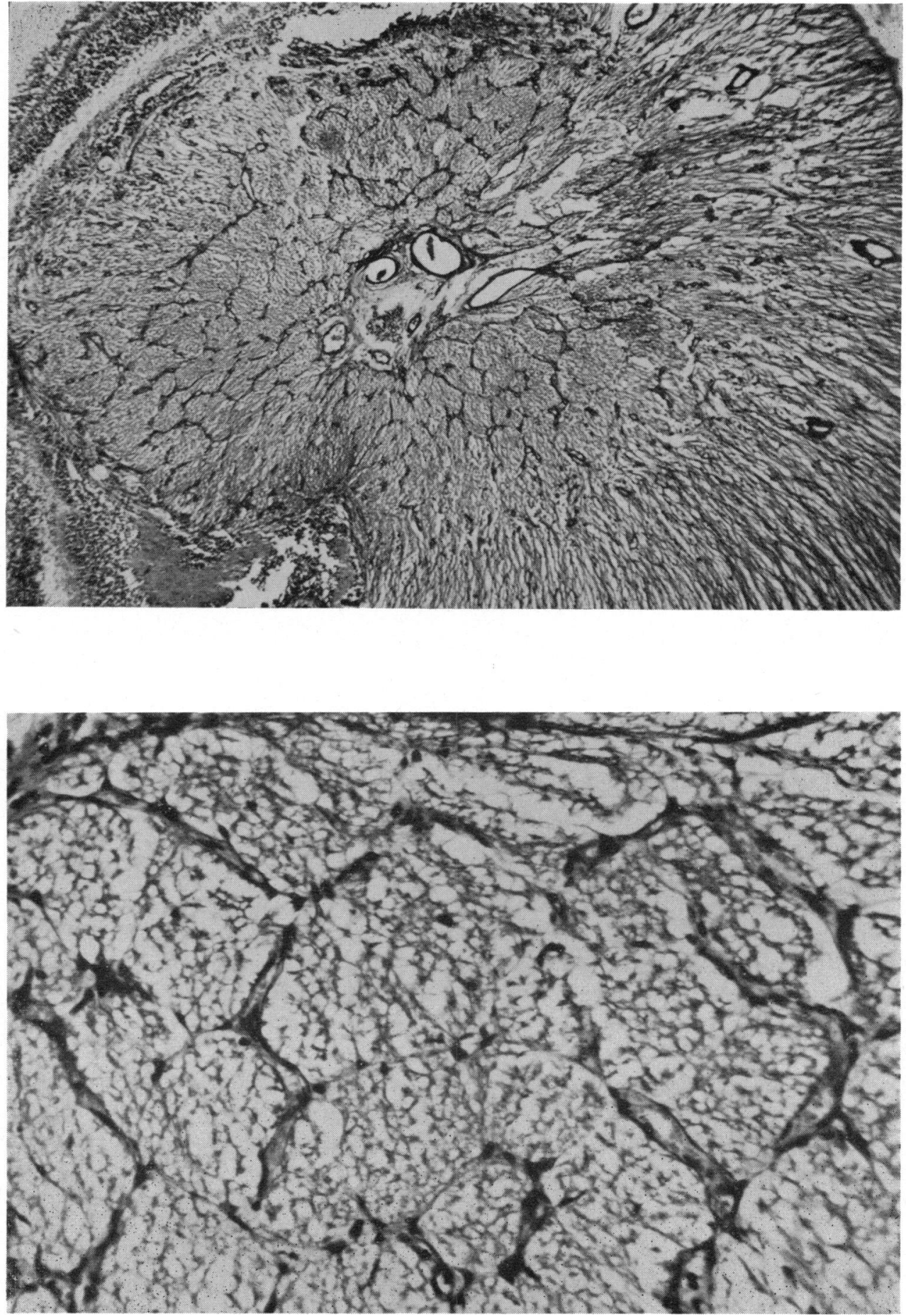

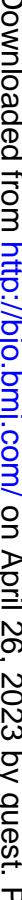

FI G. I 6 Histological sections of prelaminar region of the optic disc of a patient with oedema of the disc, showing capillaries two or three times the normal diameter [Reproduced by courtesy of Dr. Paul Henkind]
(a) $\times 3^{8}$
(b) $\times 240$ 
There is a distinct entity seen mostly in young adults which consists of unilateral oedema of the disc with markedly engorged retinal veins and venous stasis, and some blurring of vision subjectively with a normal or defective visual acuity objectively; the deterioration of vision is usually not gross. A careful search in a few of these patients has revealed some signs of mild uveitis with no other ocular or systemic abnormality. I have found that such cases usually respond well to systemic corticosteroids. Since unilateral oedema of the disc and venous engorgement dominate the picture in this condition, these patients have been diagnosed differently by different observers, e.g. retinal vasculitis (Lyle and Wybar, 196r), central retinal vein occlusion, and unilateral oedema of the optic disc of obscure origin. The fact that there is usually a favourable response to corticosteroids favours an inflammatory aetiology. I feel that this is possibly another variant of oedema of the optic disc due to uveitis with secondary retinal venous involvement or vice versa. It may, in fact, be vasculitis of the optic disc.

Acute rises in intraocular pressure, e.g. acute congestive glaucoma, are accompanied by oedema of the optic disc. This is presumably due to compression of vessels in the prelaminar region producing anoxia which in turn would lead to oedema.

Ischaemic optic neuropathy with a pale oedema of the optic disc is a well documented condition (Fig. I 7). It is seen mostly in elderly persons. The retinal vessels are normal for the age. There is a sudden complete loss of vision or development of a variety of visual field defects, e.g. central, altitudinal, or sectoral defects or peripheral constriction. This is caused in most cases by temporal arteritis but may be due to arteriosclerotic occlusive disorder (Cullen, 1967). The pathogenesis of the pale oedema of the optic disc and the visual loss in this condition has been debated by various authors. The basic lesion is the occlusion of the posterior ciliary arteries, which produces infarction not only of the disc but also of the retrobulbar part of the optic nerve by virtue of their distribution to the prelaminar and lamina cribrosa regions of the optic disc and the adjacent optic nerve. In patients with cilio-retinal arteries (Fig. I 7), the retinal area supplied by these vessels is also seen to be involved. The infarction of the optic disc leads to the pale oedema.
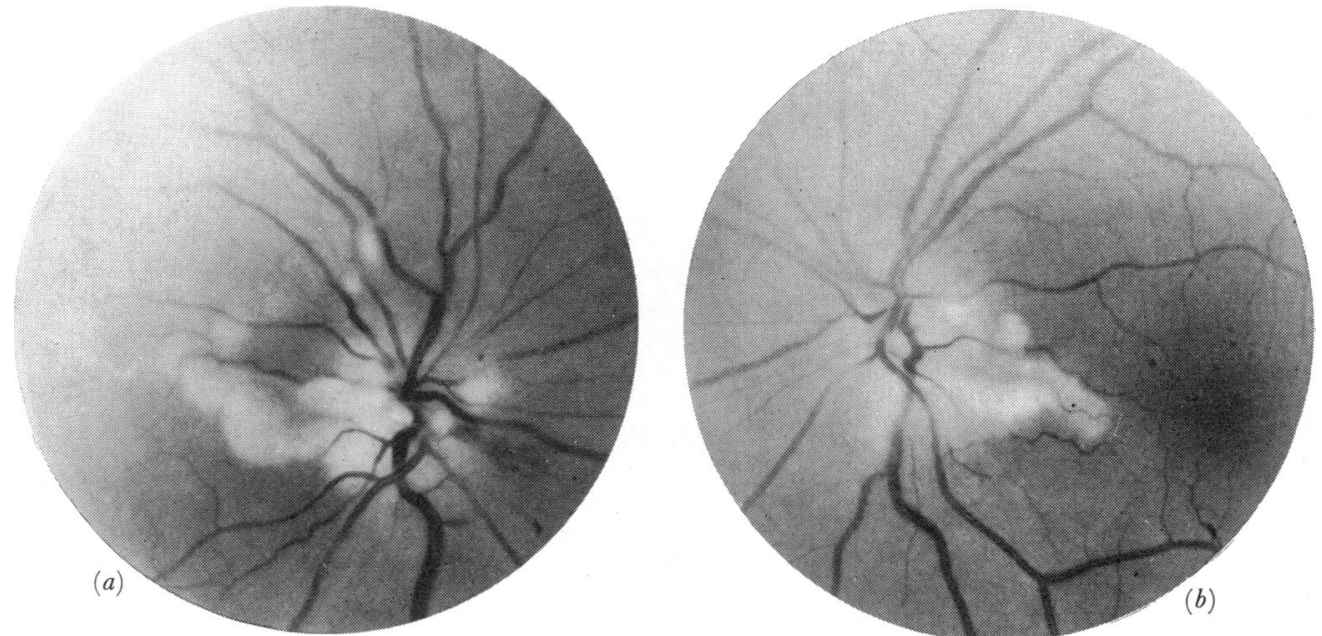

FIG. 17 Right (a) and left (b) eyes of a 68-year-old woman with temporal arteritis. Sudden loss of vision occurred in both eyes at an interval of 4 days. Note the pale oedema of the disc and the retinal infarct in the inferior temporal quadrant of both eyes. The area of the retinal infarct is that supplied by the cilio-retinal artery in each case. Fluorescence fundus angiography revealed normal retinal circulation but no filling of the cilioretinal arteries and the choroidal contribution to the disc. [Published by courtesy of Prof. D. W. Hill] 
The area of the disc involved depends upon the extent of posterior ciliary artery involvement, i.e. the occlusion of the main posterior ciliary arteries produces extensive infarction of the disc, but involvement of one small branch leads to a sectoral lesion. The lesion may progressively involve more and more of the peripapillary choroid. The literature contains many histopathological reports showing the involvement of the posterior ciliary arteries by temporal arteritis and infarction in the optic nerve. The pale oedema involving only the optic disc can be produced only by occlusion of the ciliary arterial supply to the disc and not by an occlusion of the central retinal artery; the latter would produce a generalized oedema of the retina.

Since the oedematous tissue in oedema of the optic disc is mainly the prelaminar tissue, it not only swells forwards but also to the sides. This sideways extension leads to displacement and detachment of the peripapillary retina. These retinal changes produce the enlargement of the blind spot so characteristic of oedema of the disc.

It is possible that long-standing oedema of the disc may produce secondary atrophic changes in the peripapillary choroid which may in turn help to produce concentric constriction of the peripheral fields and other field defects and optic atrophy.

The facts that the optic disc is supplied mainly by the ciliary circulation in the vast majority of subjects, and that the peripapillary choroid has an important role to play in this and is very susceptible to compression and to atrophic and degenerative processes, open an entirely new field. Some of the speculations mentioned in this paper need to be confirmed or rejected by future studies.

\section{Summary}

In the normal optic disc in man, the blood supply to the lamina cribrosa and the prelaminar regions is derived from the ciliary circulation, and that to the surface nerve fibre layer is a part of the retinal circulation.

Fluorescence of the normal optic disc in fluorescence fundus angiography is greatest during the arteriovenous phase of the transit of the dye. The intensity of redness of the disc and of its fluorescence has a different distribution in 70 per cent. of cases.

The fluorescence patterns of optic atrophies due to different causes are described. The fluorescence of the disc is reduced in these cases.

Acute elevation of the intraocular pressure in monkeys selectively obliterates the vessels of choroidal origin in the optic disc and the peripapillary choroid; there is also reduced filling of the rest of the choroid but without any obliteration of the retinal vasculature. The role of choroidal circulation in the pathogenesis of visual field defects, optic disc changes, and cavernous degeneration of the optic nerve in glaucoma is discussed.

Studies in patients with oedema of the optic disc suggest that the oedema precedes the vascular changes in the optic disc and the adjoining retina. The role of the ciliary circulation in the pathogenesis of oedema of the optic disc of different origins is discussed.

I am grateful to Prof. E. S. Perkins for his valuable comments and help and to Prof. B. R. Jones for the facilities given to me for this work; to the Department of Audio-visual Communications of the Institute of Ophthalmology for the illustrations; to Mrs. Susan Zimmerman for secretarial help; and to Mr. John Edwards for technical assistance in the experimental work.

\section{References}

Alterman, M., and henkind, P. (ig68) Brit. J. Ophthal., 52, 26

BONAMOUR, G., BRÉgeAt, P., BONNET, M., and JUGe, P. (I968) “La papille optique”, pp. I I-I 5, 46, 193, $362-363,426$. Masson, Paris 
COATs, G. (1906) Ophthal. Rev., 25, 99

GRISTINI, G. (195I) Brit. F. Ophthal., 35, II

CULLEN, J. F. (1967) Trans. ophthal. Soc. U.K., 87, 759

DAVID, N. J. (1969) "Proc. Int. Symp. on Fluorescein Angiography, Albi" (in press)

- Norton, E. W. D., Gass, J. D., and beauchamp, J. (1967) Arch. Ophthal. (Chicago), 77, 619 Dollery, c. T., MAIler, c. M., and hOdge, J. v. (1965) J. Neurol. Neurosurg. Psychiat., 28, 24I DUKE-ELDER, s. (I96I) "A System of Ophthalmology", vol. 2, pp. 357-358. Kimpton, London elschnig, A. (1888) Arch. Augenheilk., 18, 295

- (1928) In "Handbuch der speziellen pathologischen Anatomie und Histologie", ed. F.

Henke and O. Lubarsch, vol. i I (Auge), pt. I, p. 873. Springer, Berlin

ERNest, J. T., and POTTS, A. M. (1968) Amer. F. Ophthal., 66, 380

FRANÇOIS, J., and NEETENS, A. (1964) Arch. Ophthal. (Chicago), 71, 219

124-145. Éditions Arscia, Brussels

GAss, J. D. M. (1969) Arch. Ophthal. (Chicago), 80, 535

Gitter, K. A., BLUmenthal, M., Galin, M. A., and Best, M. (1969) "Proc. Int. Symp. on Fluorescein

Angiography, Albi" (in press)

HALLER, A. VON (1754) “Arteriarum oculi historia et tabulae arteriarum oculi”. Göttingen

hamasaki, D. I., and Fujino, T. (1967) Arch. Ophthal. (Chicago), 78, 369

haRRINGton, D. c. (1959) Amer. F. Ophthal., 47, No. 5, pt 2, p. 177

HAYREH, s. S. (1958) "A study of the central artery of the retina in human beings in its intraorbital and intraneural course". M.S. Thesis, Panjab University, India.

(1962a) Brit. F. Ophthal., 46, 212

- (1962b) "XIX Conc. Ophthal. 1962. India (New Delhi) Acta", vol. 2, p. I194

(published 1966)

(1963a) Anal. Inst. Barraquer, 4, 7

(1963b) Brit. 7. Ophthal., 47, 71

(1963c) Ibid., 47, 65I

(1965) "Pathogenesis of Oedema of the Optic Disc (Papilloedema)". Ph.D. Thesis,

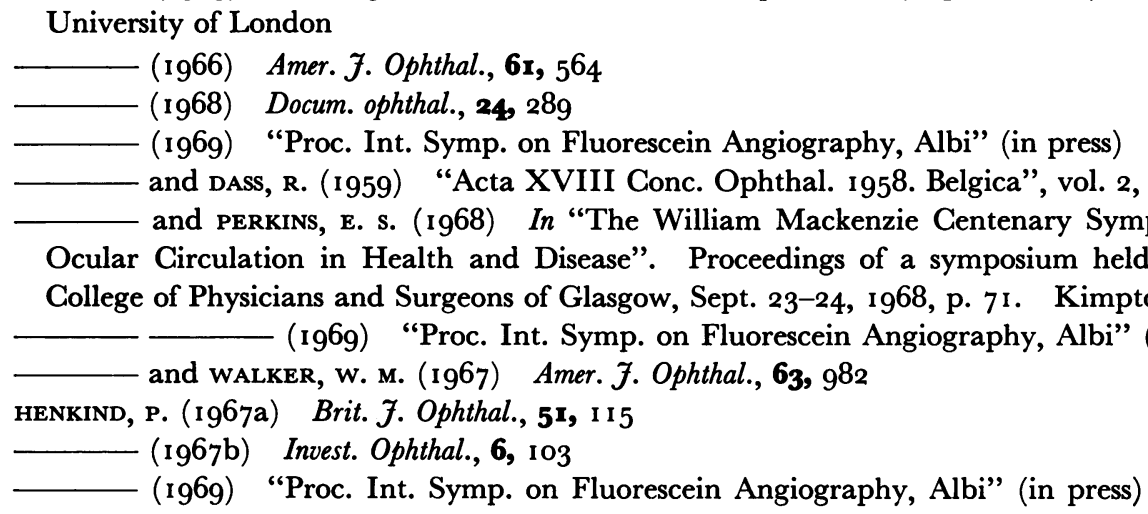

HILL, D. W. (1966) Trans. ophthal. Soc. U.K., 86, 125

hoYt, W. F., and BeEston, D. (1966) “The Ocular Fundus in Neurologic Disease", p. 42. Mosby,

St. Louis

Kalvin, N. H., hamasaki, D. I., and Gass, J. D. m. (1966) Arch. Ophthal. (Chicago), 76, 94

KORNZWEIG, A. L., ELIASOPH, I., and FELDSTEIN, M. (I968) Ibid., 80, 696

KROLL, A. J. (1968) Ibid., 79, 453

LAWFORD, J. B. (1895) Trans. ophthal. Soc. U.K., 15, 195

LYLE, T. K., and WYBAR, K. (196I) Brit. F. Ophthal., 45, 778

michaelson, I. G., and CAmpbell, A. C. P. (1940) Trans. ophthal. Soc. U.K., 60, 7 I

MILLER, S. J. H., SANDERS, M. D., and FFYTCHE, T. J. (1965) Lancet, 2, 65 I 
o'DAy, D., GRock, G., GAlbraith, J. E. K., PARel, J. M., and Wigley, A. (1967) Ibid., 2, 224 PARsons, J. H. (1906) "The Pathology of the Eye", vol. 3, pt I, p. 865. Hodder and Stoughton, London

Rosen, E. s., and Ashworth, B. (1968) F. Neurol. Neurosurg. Psychiat., 31, 253

SANDERS, M. D. (1969) Trans. ophthal. Soc. U.K., 89 (in press)

SGHNABEL, J. (1892) Arch. Augenheilk., 24, 273

shikano, s., and shimizu, к. (I968) "Atlas of Fluorescence Fundus Angiography", pp. 34-49.

Igaku Shoiu, Tokyo

SINGH, s., and DASS, R. (1960) Brit. F. Ophthal., 44, I93, 280

SNYDER, W. B., Allen, L., and Frazier, o. (1967) Arch. Ophthal. (Chicago), 77, 68

WOLFF, E. (1947) Trans. ophthal. Soc. U.K., 67, 133

WYBAR, K. c. (1954) Brit. 7. Ophthal., 38, 513

z INN, J. G. (I 755) "Descriptio anatomica oculi humani". Vandenhoeck, Göttingen 